\title{
Observando la mentalización en psicoterapias con adolescentes: Diseño de un sistema de observación de la interacción terapéutica*
}

\section{Observing Mentalization in Psychotherapies with Adolescents: Design of an Observational System for Therapeutic Interaction}

\author{
Javier Morán Kneer ${ }^{1}$ ORCID , Claudio Martínez Guzmán ${ }^{2}$, María Francisca Díaz ${ }^{3}$, Silvia González \\ Chamorro $^{4}$, Karla Arce Beas ${ }^{5}$, Javiera Duarte ${ }^{6} \underline{0 R C I D}$ \\ 134 Universidad de Valparaíso \\ 126 Instituto Milenio para la Investigación en Depresión y Personalidad (MIDAP). \\ 126 Universidad Diego Portales \\ Chile
}

Fecha correspondencia:

Recibido: noviembre 18 de 2019.

Aceptado: septiembre 14 de 2020.

Forma de citar:

Morán, J., Martínez, C., Díaz,

M.F., González, S., Arce, K., \&

Duarte, J. (2020). Observando la

mentalización en psicoterapias

con adolescentes: Diseño de un

sistema de observación de la

interacción terapéutica. Rev. CES

Psico, 13(3), 51-75.

Open access

(c) Copyright

Licencia creative commons

Ética de publicaciones

Revisión por pares

Gestión por Open Journal System

DOl: http://dx.doi.org/10.21615/

cesp.13.3.4

ISSN: 2011-3080
Comparte

\section{Resumen}

Objetivo: Basado en la falta de medidas que permitan evaluar la mentalización como variable de proceso en psicoterapias con adolescentes, el siguiente estudio apunta a presentar el diseño de un sistema observacional para evaluar el despliegue de esta variable tanto en pacientes como en terapeutas. Método: mediante el proceso de codificación abierta de la teoría fundamentada y análisis temático de tres niveles, se analizó el despliegue de la mentalización tanto en terapeutas como en pacientes en 10 episodios de ruptura y 10 episodios de resolución elegidos aleatoriamente de cinco psicoterapias con adolescentes. Resultados: A partir del análisis efectuado se desarrolló un sistema observacional de seis dimensiones emergentes (foco en los estados mentales, opacidad de los estados mentales, comunicación contingente, causalidad de los estados mentales, naturaleza dinámica de los estados mentales y foco en el momento presente) denominado "Sistema de Observación de la mentalización en Psicoterapia con adolescentes" (OMP-A) que permite evaluar cuantitativamente la mentalización de terapeutas y pacientes. Discusión y conclusiones: el OMP-A es un instrumento que responde a debilidades de otros sistemas para evaluar mentalización en psicoterapia con adolescentes, permitiendo la observación de aspectos lingüísticos y paralingüísticos del mentalizar y toma en consideración aspectos particulares que caracterizan las intervenciones con adolescentes. Se discute su posible uso para la formación y supervisión en psicoterapia, y los desafíos metodológicos para desarrollos futuros.

Palabras Clave: Mentalización, Tratamiento basado en la Mentalización, Psicoterapia con Adolescentes, Investigación de Proceso en Psicoterapia. 
Pág 52

Sobre el artículo:

Este trabajo fue financiado por ANID - Iniciativa Científica Milenio / Instituto Milenio para la Investigación en Depresión y Personalidad-MIDAP ICS13_005.

Sobre los autores:

1. Doctor en Psicoterapia, Magíster en Psicología de la Adolescencia, Psicólogo. Profesor Adjunto, Escuela de Psicología, Universidad de Valparaíso. Investigador Joven, Instituto Milenio para la Investigación en Depresión y Personalidad (MIDAP). Investigador Centro de Estudios en Psicología Clínica y Psicoterapia (CEPPS), Universidad Diego Portales.

2. Doctor en Psicología, Magister en Psicología Clínica, Psicólogo. Profesor titular Facultad de Psicología Universidad Diego Portales. Investigador Asociado Instituto Milenio para la Investigación en Depresión y Personalidad (MIDAP). Director Centro de Estudios en Psicología Clínica y Psicoterapia (CEPPS), Universidad Diego Portales.

3. Magíster en Psicología Clínica. Psicólogo.

4. Magíster en Psicología Clínica, Mención Psicoterapias Constructivista y Construccionista, Psicólogo. Docente, Escuela de Psicología, Universidad de Valparaíso.

\section{Abstract}

Objective: Based on the need for measures for assessing mentalization in adolescent psychotherapy, this study aims to design an observational system to evaluate the deployment of reflective function in both patients and therapists during psychotherapy sessions. Method: 10 episodes of rupture and 10 episodes of resolution randomly chosen within 5 videotaped and transcribed psychotherapies were analyzed using grounded theory "s open coding procedure and a three-level thematic analysis. Results: An observational system with 6 emergent dimensions (focus on mental states, opacity of mental states, contingent communication, causality of mental states, dynamic nature of mental states and focus on the present moment) and a 5-point scale was developed. Discussion and conclusions: The "Observational System for mentalization adolescent psychotherapy" (OMP-A) is an instrument that responds to certain weaknesses of other instruments by considering linguistic and paralinguistic aspects of mentalization and particular aspects that characterize interventions with adolescents. It "s possible use for training and supervision is discussed as well as some methodological challenges for future research.

Keywords: Mentalization, Mentalizing, Mentalization-Based Treatment, Adolescents Psychotherapy, Process Research in Psychotherapy.

\section{Introducción}

La mentalización es un tipo de cognición social y es definida como una actividad mental preconsciente e imaginativa que permite percibir e interpretar el comportamiento humano en términos de estados mentales intencionales (Allen \& Fonagy, 2006). Así, mentalizar implica tomar conciencia de las circunstancias de uno mismo y otros, tomando en consideración patrones previos de comportamiento y experiencias a las que se ha estado expuesto (Fonagy \& Bateman, 2019).

Durante los últimos años, el estudio de la mentalización se ha extendido a diversas disciplinas tales como las neurociencias (Spunt, Satpute, \& Lieberman, 2011), la psicología del desarrollo (Meins, Fernyhough, Rosnay, Arnott, \& Leekam, 2012), la psicología cognitiva (Ruffman, Slade, \& Crowe, 2002) y la psicoterapia (Bateman \& Fonagy, 2012), entre otras; hasta el punto de establecerse como un programa de investigación integrador y de amplio poder explicativo para la comprensión del vínculo entre las experiencias tempranas de apego y el surgimiento de estructuras neurobiológicas (Frith \& Frith, 2003; Schore \& Schore, 2007), y procesos mentales (Sharp \& Fonagy, 2008) que permiten la regulación de los afectos y la organización del self (Fonagy, Gergely, Jurist, \& Target, 2002).

Particularmente, el estudio de la mentalización en la adolescencia se ha constituido en un marco de referencia relevante para comprender las vicisitudes de esta etapa, aportando evidencia que permite identificar los cambios neurobiológicos normativos de este periodo como factores de vulnerabilidad y/o resiliencia para el desarrollo de psicopatologías (Hauser, Allen, \& Golden, 2006). Por otro lado, ha tenido fuerte impacto en el campo de la psicoterapia con adolescentes, tanto a nivel de las intervenciones individuales (Rossouw, 2015), como las familiares (Asen \& Fonagy, 2012) y grupales (Bo et al, 2017), hasta el punto de plantearse como una variable genérica para el cambio en dichas intervenciones (Rossouw \& Fonagy, 2012); en especial, en el trabajo con jóvenes diagnosticados con trastornos de desarrollo limítrofe de la personalidad y que presentan comportamientos autolesivos. Si bien la evidencia de los estudios de la mentalización en psicoterapia con adolescentes es prometedora, 
5. Magíster en Psicología

Clínica, Psicólogo.

6. Doctora en Psicoterapia, Magister en Psicología

Clínica de Adultos,

Psicóloga. Profesora

Facultad de Psicología

Universidad Diego Portales.

Investigadora Joven,

Instituto Milenio para la

Investigación en Depresión

y Personalidad (MIDAP).

Investigadora Centro de

Estudios en Psicología

Clínica y Psicoterapia,

Universidad Diego Portales

(CEPPS-UDP).

Un paso necesario para avanzar en la investigación en mentalización con adolescentes en psicoterapia, consiste en el desarrollo de medidas que se ajusten a las particularidades de las intervenciones con este grupo etario: por ejemplo, la conversación tiende a ser menos fluida y espontánea que con los adultos, se presentan múltiples desconexiones de la interacción (Binder, Holgersen, \& Høstmark, 2008), silencios (Gensler, 2015) y, en general, menor motivación hacia la psicoterapia (McLeod et al, 2016). aún es escasa y contrasta fuertemente con la cantidad de investigación existente con adultos; una brecha importante disminuir (Bevington et al, 2013).

Un paso necesario para avanzar en la investigación en mentalización con adolescentes en psicoterapia, consiste en el desarrollo de medidas que se ajusten a las particularidades de las intervenciones con este grupo etario: por ejemplo, la conversación tiende a ser menos fluida y espontánea que con los adultos, se presentan múltiples desconexiones de la interacción (Binder, Holgersen, \& Høstmark, 2008), silencios (Gensler, 2015) y, en general, menor motivación hacia la psicoterapia (McLeod et al, 2016). A esto se suma que, debido a diversos cambios neurobiológicos propios de esta etapa (Sharp \& Fonagy, 2015), es común observar en los adolescentes mayor vulnerabilidad a quiebres en el funcionamiento de su capacidad mentalizadora (Bleiberg, Rossouw, \& Fonagy, 2012). Así, la naturaleza relacional, esencialmente cambiante, y contextualmente dependiente de la mentalización (De la Cerda, Martínez \& Tomicic, 2018), se hace evidente a lo largo de las intervenciones clínicas con este grupo etario. Por lo tanto, uno de los principales desafíos para la investigación en psicoterapia con adolescentes consiste en el desarrollo de instrumentos que capten aspectos relacionales, no verbales y en contexto (Vrouva, Target, \& Ensink, 2013).

En estudios sobre mentalización en psicoterapia con adultos, la Escala de Función Reflexiva [RFS] (Fonagy, Target, Steele, \& Steele, 1998) aplicada durante la Entrevista de Apego Adulto [AAl, por sus siglas en inglés de Adult Attachment Interview] (Main, Goldwyn, \& Hesse, 2003), ha cumplido un rol destacado en diseños de investigación pre-post (Gullestad, \& Wilberg, 2011; Fischer-Kern et al, 2015) o como medida mediadora/moderadora (Levy, et al 2006; Gullestad et al 2013). Aun así, esta aproximación no ha estado exenta de críticas, las cuales se han focalizado principalmente sobre sus limitaciones para capturar aspectos dialógicos y relacionales característicos de la psicoterapia, debido al foco estático del protocolo de la AAI sobre aspectos más bien estables de la personalidad (Katznelson, 2014). Como respuesta, sólo recientemente, a partir de la adaptación de la RFS al campo de la psicoterapia (eg. Hörz-Sagstetter et al., 2015; Martínez et al., 2017, Talia et al., 2019) se han comenzado a realizar estudios de proceso en psicoterapia, un aporte significativo que ha permitido evaluar el despliegue de la mentalización momento a momento durante las intervenciones clínicas.

Pese a lo prometedor de estos avances, en el campo de la investigación del proceso terapéutico con adolescentes persiste la necesidad de desarrollar instrumentos que sean sensibles a aspectos interactivos e implícitos, en los cuales se encarna la mentalización, más allá del foco en lo verbal que ha primado en la investigación con adultos en esta área. Por lo tanto, el siguiente estudio tiene como objetivo presentar el desarrollo de una medida de observación, en su versión piloto, para evaluar la mentalización de terapeutas y pacientes adolescentes en procesos de psicoterapia.

\section{Método}

Se realizó una investigación cualitativa, de tipo descriptiva, orientada a describir el proceso de construcción de un instrumento de observación de la mentalización en psicoterapia. La unidad de análisis correspondió a episodios de ruptura y resolución de la alianza terapéutica (Safran \& Muran, 2005), dentro de los cuales se identificaron indicadores de mentalización. El análisis se llevó a cabo mediante la teoría fundamentada, particularmente a través del proceso de codificación abierta (Charmaz, 2014), que posteriormente dio origen a seis dimensiones de la mentalización. 


\section{Muestra y Procedimiento}

Los episodios de ruptura y resolución fueron seleccionados de cinco procesos de psicoterapia con adolescentes. Tal como proponen Safran y Muran (1996), un episodio de ruptura corresponde a un segmento de la interacción terapéutica en el cual es posible identificar en los pacientes un indicador de retirada o confrontación, que impacta negativamente sobre el establecimiento de la alianza terapéutica. La resolución, por su parte, corresponde a un momento caracterizado por acciones que establece el terapeuta para hacer frente a las rupturas.

Este tipo de episodios, caracterizados por la tensión relacional entre ambos actores, son frecuentes en las psicoterapias con adolescentes (Morán, Díaz, Martínez, Varas, \& Sepúlveda, 2019) y ha sido identificada su relevancia para el despliegue de la mentalización en psicoterapia con adolescentes (Morken, Karterud, \& Arefjord, 2014; Lingiardi \& Colli, 2015), dado que genera un contexto de estrés que exige su uso. Por lo anterior, este tipo de episodios son escenarios interaccionales idóneos para observar el funcionamiento reflexivo tanto de pacientes como de terapeutas.

Para la identificación de los episodios de ruptura y resolución, cuatro parejas de codificadores independientes, entrenados en el Ruputre Resolution Rating System (3RS, Eubanks-Carter, Safran, \& Muran, 2014), evaluaron cinco procesos psicoterapéuticos con adolescentes previamente videograbados y transcritos (ver Tabla 1). Los cinco consultantes presentaron sintomatología depresiva leve a moderada, evaluada a través del Beck Depression Inventory (BDI-IA, Valdés et al., 2017); y adicionalmente, uno de ellos, cumplió con los criterios para el diagnóstico de desarrollo limítrofe de la personalidad.

De un total de 61 episodios de ruptura-resolución identificados, se seleccionaron aleatoriamente dos episodios de ruptura y dos episodios de resolución de cada proceso terapéutico, quedando conformada la muestra por 10 episodios de ruptura y 10 episodios de resolución.

Todos los pacientes firmaron el consentimiento informado, y los menores de 18 años firmaron el asentimiento y un adulto responsable firmó el consentimiento respectivo. Los investigadores firmaron un compromiso de confidencialidad, y en la redacción de los resultados se omitió referenciar al paciente citado y se modificaron los datos que permitieran identificarlo. El estudio contó con la aprobación del comité de Bioética de la Facultad de Medicina de la Universidad de Chile.

Tabla 1. Descripción de las psicoterapias analizadas

\begin{tabular}{cccccc}
\hline Terapia & Sexo T-P & Edad paciente & $\begin{array}{c}\text { Estado del } \\
\text { proceso }\end{array}$ & $\begin{array}{c}\text { Cantidad de } \\
\text { Sesiones }\end{array}$ & $\begin{array}{c}\text { Enfoque } \\
\text { terapéutico }\end{array}$ \\
\hline 1 & F - F & 14 & Alta & 10 & TAU \\
\hline 2 & F - F & 15 & Deserción & 15 & TCC \\
\hline 3 & F - F & 17 & Deserción & 8 & TCC \\
\hline 4 & M - M & 18 & Alta & 9 & Integrativo \\
\hline 5 & F - M & 19 & En proceso & 54 & Psicodinámico \\
\hline
\end{tabular}

$\mathrm{TAU}=$ Treatment as usual; $\mathrm{TCC}=$ Terapia Cognitiva Conductual 
En el proceso de análisis se tomó en consideración la definición del concepto de mentalización de Bateman y Fonagy (2004): "procesos mentales a través de los cuales un individuo implícita y explícitamente interpreta las acciones de sí mismo y otros con significado basado en estados mentales intencionales tales como deseos, emociones, creencias y razones" (p.xxi), y las dimensiones de la Escala de Función Reflexiva (ver Fonagy, Target, Steele, \& Steele, 1998).

\section{Procedimiento de análisis}

En el proceso de análisis se tomó en consideración la definición del concepto de mentalización de Bateman y Fonagy (2004): "procesos mentales a través de los cuales un individuo implícita y explícitamente interpreta las acciones de sí mismo y otros con significado basado en estados mentales intencionales tales como deseos, emociones, creencias y razones" (p.xxi), y las dimensiones de la Escala de Función Reflexiva (ver Fonagy, Target, Steele, \& Steele, 1998). Además, se mantuvo un criterio de apertura al descubrimiento de indicadores de mentalización de acuerdo con la definición asumida en el presente estudio.

El procedimiento de análisis se realizó en tres niveles de especificidad, con el fin de ir generando categorías emergentes relacionadas con el la mentalización tanto del paciente como del terapeuta. La Figura 1 ejemplifica los dos primeros niveles de dicho procedimiento.

El primer nivel de análisis consistió en la realización de un resumen escrito consensuado de cada episodio que contiene la descripción de interacciones verbales que evidencian el acto de imaginar estados mentales intencionales en ambos participantes. Para este análisis se tomaron en consideración, tal como proponen Braun y Clarke (2006), aspectos lingüísticos, paralingüísticos y contextuales.

Este análisis fue realizado en su totalidad por el primer autor del presente artículo, quien está entrenado en terapia para adolescentes basada en la mentalización y en la interpretación de la Escala de Función Reflexiva, y una psicóloga clínica con experiencia en métodos cualitativos y en psicoterapia con adolescentes

El segundo nivel de análisis se llevó a cabo con base en la descripción consensuada del nivel uno, buscando determinar de manera concreta y observable qué acciones de los terapeutas promovían u obstaculizaban/afectaban la mentalización de los pacientes; y las consecuentes respuestas de éstos. Este análisis se articuló en función de las siguientes preguntas guía:

1. ¿Qué acciones de los terapeuta promueven la mentalización del paciente?

2. ¿Qué acciones de los terapeuta no promueven la mentalización del paciente?

3. ¿Qué respuestas de los pacientes ante las intervenciones de sus terapeutas evidencian una postura mentalizadora?

4. ¿Qué respuestas de los pacientes ante las intervenciones de sus terapeutas evidencian una postura no-mentalizadora'?

Las respuestas a estas preguntas fueron luego analizadas mediante el procedimiento de codificación abierta de la teoría fundamentada (Charmaz, 2014), con el fin de generar categorías emergentes relacionadas con la mentalización tanto del paciente como del terapeuta. Este trabajo permitió a los codificadores identificar 42 indicadores de mentalización tanto para pacientes como para terapeutas, tales como: "hace referencia a motivaciones, emociones o creencias en uno mismo u otros", "impone su punto de vista", "sintoniza con el afecto", "promueve/evidencia una reflexión en el presente", "demanda/evita reflexionar".

1. Se utiliza la distinción "postura mentalizadora" (mentalizing stance) y "postura no-mentalizadora" (non mentalizing stance) basados en el concepto utilizado originalmente (ver Bateman \& Fonagy, 2004). Estos mismos autores han descrito tres posturas no-mentalizadoras prototípicas: "modo como si", "modo teleológico", "equivalencia psíquica" (ver Bateman y Fonagy, 2006). Debido al uso de un método abierto al descubrimiento, este nivel utiliza el concepto "no-mentalizador" como opuesto a "mentalizador"; no como sinónimo de estos tres modos descritos en la literatura. 


\begin{tabular}{|c|c|c|c|c|c|}
\hline \\
\hline \multirow{2}{*}{\multicolumn{2}{|c|}{$\begin{array}{l}\text { T: hola } \\
\text { P: hoy día estoy mal } \\
\text { T: qué te pasa? } \\
\text { P: ayer me pagaron poco y no me } \\
\text { alcanza para nada, y hoy tuve examen } \\
\text { me fue mal y, estoy cansado ya no } \\
\text { quiero nada (já) } \\
\text { T: no tenías ganas de venir } \\
\text { P: no tengo ganas de hacer nada - no } \\
\text { sé si es por estrés no sé pero } \\
\text { T: y eso te pasa frecuentemente? } \\
\text { P: a veces...la semana pasada empezó } \\
\text { y esta semana también. Estoy chato, } \\
\text { agotado, duermo mal, estudio hasta } \\
\text { tarde, me quedo hasta como las cuatro } \\
\text { de la mañana estudiando, estoy súper } \\
\text { agotado } \\
\text { T: y a qué lo: a qué lo asocias tú? }\end{array}$}} & \multicolumn{2}{|c|}{$\begin{array}{l}\text { P: creo que es por porque estoy } \\
\text { estudiando mucho o muy tarde no } \\
\text { sé. Estoy súper "choreado". } \\
\text { T: pero esto te está pasando hace un } \\
\text { par de semanas me dijiste } \\
\text { P: m-hm es que la semana pasada } \\
\text { también estuve con "full" pruebas } \\
\text { entonces no he dormido bien no he } \\
\text { podido descansar } \\
\text { lo que quiero descansar, porque el } \\
\text { fin de semna estudio en la mañana, } \\
\text { entonces no duermo bien... muy } \\
\text { agotado } \\
\text { T: y no duermes bien qué significa? } \\
\text { P: que no me acuesto o sea no } \\
\text { duermo mis horas que tengo que } \\
\text { dormir }\end{array}$} & \multicolumn{2}{|c|}{$\begin{array}{l}\text { T: te acuestas muy tarde te levantas más } \\
\text { temprano te despiertas en la noche. qué } \\
\text { te pasa? } \\
\text { T: tú lo asocias solamente a al estudio y } \\
\text { a las pruebas? } \\
\text { P: yo creo que sí o sea igual: } \\
\text { T: yo pensaba que esta situación ... que } \\
\text { te parece a ti porque estás iniciando un } \\
\text { proceso estás conmigo. no solamente } \\
\text { eso además hay cámara } \\
\text { P: m-m sí pero no si no es por eso } \\
\text { T: has pensado en eso no? } \\
\text { P: no (já) es que intento no pescar esas } \\
\text { cosas +(risa)+ porque como que no } \\
\text { (risa) me intento imaginar que no que } \\
\text { solo los dos nada más }\end{array}$} \\
\hline & & & refiere malestar por estrés vivido últimamente. T busca profun & & \\
\hline \multicolumn{6}{|c|}{$\begin{array}{l}\text { P refiere malestar por estrés vivido últimamente. T busca profundizar en la comprensión de este estado, originalmente } \\
\text { descrito por P de manera general. Las intervenciones buscan indagar sobre la organización temporal de eventos que } \\
\text { llevaron a este estado en la actualidad ("y a que lo asocias tu?", "pero eso te está pasando hace un par de semanas"). Este } \\
\text { tipo de preguntas promueven que P vuelva a recordar eventos estresantes recientes y refiere más de una vez que: "esta } \\
\text { agotado". Luego T indaga sobre el significado personal que otorga el } \mathrm{P} \text { a ciertos eventos ("y no duermes bien, que } \\
\text { significa?"). Hacia el final del episodio T invita a buscar otras causas, proponiendo una relación entre asistir a terapia en } \\
\text { un contexto que además es videado y este malestar, ante lo que el } \mathrm{P} \text { explicita su falta de motivación a reflexionar sobre } \\
\text { este punto. }\end{array}$} \\
\hline \multicolumn{6}{|c|}{ Nivel 2} \\
\hline $\begin{array}{l}\text { de la } \\
\text { una } \\
\text { bre } \\
\text { bre } \\
\text { mir }\end{array}$ & & & & & $\begin{array}{l}\text { ncada } \\
\text { un } \\
\text { cto en } \\
\text { un } \\
\text { ción } \\
\text { uede } \\
\text { ce } \\
\text { icita }\end{array}$ \\
\hline \multicolumn{6}{|c|}{ Indicadores emergentes de mentalización } \\
\hline - & & & a & & \\
\hline
\end{tabular}

Figura 1. Ejemplo de proceso de codificación

Finalmente, en el tercer nivel de análisis, 42 indicadores de mentalización identificados y sus propiedades fueron discutidos y consensuados a través de acuerdo intersubjetivo (Flick, 2009) y clasificados en categorías mayores. Esto dio como resultado el origen de seis dimensiones de la mentalización: foco en los estados mentales; opacidad de los estados mentales; comunicación contingente; naturaleza dinámica de los estados mentales; causalidad de los estados mentales; y foco en el momento presente.

Todo el proceso de análisis, ilustrado en la Figura 1 fue desarrollado por dos codificadores (PhD. Ps. Javier Morán y MCs. Ps. Francisca Díaz) y auditado (Tobin \& Begley, 2003) por un investigador especialista en métodos cualitativos y más de 25 
El desarrollo del sistema de evaluación, denominado "Observando la Mentalización en Psicoterapia con Adolescentes" [OMP-A] se basó en los resultados cualitativos emergentes; de esta manera, cada una de las seis dimensiones de la mentalización que surgieron a partir del análisis cualitativo, dio origen a las dimensiones del OMP-A. años de experiencia como psicoterapeuta (PhD. Ps. Claudio Martínez), quien entregó orientaciones a lo largo del proceso de análisis respecto a la pertinencia clínica de los resultados emergentes.

\section{Elaboración del sistema de evaluación de la mentalización}

El desarrollo del sistema de evaluación, denominado "Observando la Mentalización en Psicoterapia con Adolescentes" [OMP-A] se basó en los resultados cualitativos emergentes; de esta manera, cada una de las seis dimensiones de la mentalización que surgieron a partir del análisis cualitativo, dio origen a las dimensiones del OMP-A.

La construcción de cada dimensión de este sistema de evaluación, se llevó a cabo a partir de sus indicadores de mentalización, los que fueron organizados en un continuo de 5 puntos, tanto para pacientes como terapeutas (Ver anexo 1). Basado en criterios clínicos, se establecieron descriptores con puntaje "1" para interacciones con el nivel más bajo de mentalización, puntaje " 3 " para interacciones que se espera sean frecuentes y evidencien un nivel incipiente de mentalización, y "5" para interacciones con el más alto nivel de mentalización esperable.

Un segundo precepto para la construcción de las dimensiones del OMP-A fue redactar las intervenciones de los terapeutas en términos de "acciones que promueven/no promueven" la mentalización de los pacientes; y las respuestas de los pacientes a las acciones de los terapeutas en términos de "respuestas que evidencian intentos por mentalizar o no mentalización en este proceso".

Finalmente, un tercer criterio consistió en que los puntajes de ambos actores fueran equivalentes.

El proceso de construcción del sistema OMP-A fue auditado por PhD Howard Steele, investigador formador y especialista en evaluación de la Función Reflexiva a través de la RFS (HS), quien propuso cambios específicos tanto a criterios (por ejemplo, que el punto 5 de "foco en los estados mentales", corresponda a una integración de aspectos observables a estados mentales); o al nombre y sentido de dimensiones ("regulación emocional" se modificó por "foco en el momento presente").

\section{Resultados}

\section{Dimensiones para la observación de la mentalización en psicoterapia}

A continuación, se describen las seis dimensiones identificadas para la observación de la mentalización en psicoterapia con adolescentes, emergentes del análisis cualitativo. Se presenta una definición de cada dimensión y una descripción, a partir de indicadores de mentalización, de las acciones de terapeutas que promueven u obstaculizan la mentalización de pacientes, y respuestas de consultantes que evidencian intentos por mentalizar o fallas en este proceso, en respuesta a las intervenciones de los terapeutas.

Foco en los estados mentales (FEM)

Esta dimensión de la mentalización se refiere a la capacidad de terapeutas y pacientes para establecer y mantener un foco consistente sobre cogniciones-afectos relativos al mundo interno de uno mismo y otros, integrando descripciones a partir de eventos y comportamientos observables. La mera alusión a aspectos psicológicos no es suficiente para considerar que está presente la dimensión FEM (Ver Tabla 2). 
Tabla 2. Dimensión de la mentalización: Foco en los estados mentales

\begin{tabular}{llll}
\hline $\begin{array}{l}\text { Acciones del T } \\
\text { que promueven } \\
\text { mentalización del P }\end{array}$ & $\begin{array}{l}\text { Respuestas del P que } \\
\text { evidencian intento } \\
\text { por mentalizar en } \\
\text { respuesta al T }\end{array}$ & $\begin{array}{l}\text { Acciones del T que } \\
\text { fallan u obstaculizan } \\
\text { promoción de la } \\
\text { mentalización del P }\end{array}$ & $\begin{array}{l}\text { Respuestas que } \\
\text { evidencian falla } \\
\text { en respuesta } \\
\text { mentalizadora del P }\end{array}$ \\
\hline $\begin{array}{l}\text { Foco en motivaciones, emociones o creencias } \\
\text { en uno mismo u otros }\end{array}$ & $\begin{array}{l}\text { Foco en situaciones, acciones y/o objetos } \\
\text { concretas/os y observables }\end{array}$ \\
\hline $\begin{array}{l}\text { Demanda } \\
\text { reflexionar al P }\end{array}$ & $\begin{array}{l}\text { Refleja motivación por } \\
\text { reflexionar }\end{array}$ & $\begin{array}{l}\text { Se mantiene pasivo } \\
\text { frente a relato no }\end{array}$ & $\begin{array}{l}\text { Evita mentalizar } \\
\text { cuando se solicita } \\
\text { mentalizador de P. }\end{array}$ \\
\hline
\end{tabular}

Detiene discurso no

mentalizador del P

T: Terapeuta; P: Paciente

En los terapeutas, la dimensión FEM se observó, por ejemplo, a partir de acciones de demanda de la mentalización de sus pacientes, pese a la negativa de éstos, tal como se aprecia en la siguiente viñeta:

T: ¿y qué es lo peor que puede pasar si le das una oportunidad?

$P:$ no, es que no lo quiero hacer, y no he pensado en hacerlo

$T$ : y qué podría pasar, pensemos

P: porque no quiero.

En los pacientes, se observó cuando asumieron una posición reflexiva como respuesta a intervenciones 0 , como expresión espontánea; mostraron motivación intrínseca por compartir y explicar su propia experiencia, vinculándola con situaciones concretas, tal como se revela a continuación:

T: ¿el ver eso qué te parece?

$P$ : me "da lata" en verdad, porque no sé creo que como en todo tengo que pedir ayuda como para poder sentirme mejor, pero al final es como peor y siempre me pasa, o sea, porque cuando estaba discutiendo con mi pareja yo como que más le pedía ayuda.

También se identificaron acciones de los terapeutas que promueven la focalización sobre aspectos concretos y observables, interrumpen el foco sobre lo mental o sostenidamente se muestran pasivos o silentes frente a los adolescentes centrados en aspectos diferentes a los mentales. Así mismo, en ocasiones y pese a los intentos de los terapeutas por focalizar la psicoterapia sobre estados mentales, los pacientes conservaron el diálogo en un nivel descriptivo, enfocado en eventos y conductas observables. La siguiente viñeta ejemplifica esta situación en ambos actores:

$\mathrm{T}$ : ¿y te llamó la atención que te quedaras dormida durante el examen?

$P$ : cómo que después cuando lo conté, así como ¿"oye cómo te quedas dormido"?

$\mathrm{T}$ : ¿quién te comentó eso?

$P$ : mis amigos... por WhatsApp ... 0 sea, para mí no es gran cosa, pero como viéndolo que... es el examen más importante del año, ahí sí es como "cuático" (risa)

T: tú me describiste que antes de entrar estabas somnoliento. 
P: claro, o sea, de hecho, me tuve que comer como dos chocolates, pero igual me dormí (risa).

Opacidad de los estados mentales (OEM)

Corresponde al grado de incertidumbre que demuestran terapeutas y pacientes sobre la experiencia interna e intencionalidad de otros, reflejando la capacidad de evidenciar que no es posible tener acceso directo y omnisciente a la mente de otros (Ver Tabla 3).

Tabla 3. Dimensión de la mentalización: Opacidad de los estados mentales

\begin{tabular}{|c|c|c|c|}
\hline $\begin{array}{l}\text { Acciones del T } \\
\text { que promueven } \\
\text { mentalización del P }\end{array}$ & $\begin{array}{l}\text { Respuestas del } P \text { que } \\
\text { evidencian intento } \\
\text { por mentalizar en } \\
\text { respuesta al T }\end{array}$ & $\begin{array}{l}\text { Acciones del T que } \\
\text { fallan u obstaculizan } \\
\text { promoción de la } \\
\text { mentalización del P }\end{array}$ & $\begin{array}{l}\text { Respuestas que } \\
\text { evidencian falla } \\
\text { en respuesta } \\
\text { mentalizadora del P }\end{array}$ \\
\hline \multicolumn{2}{|c|}{$\begin{array}{l}\text { Expresa curiosidad por la experiencia del otro u } \\
\text { otros }\end{array}$} & \multicolumn{2}{|c|}{$\begin{array}{l}\text { Denota y/o explicita certeza de los estados } \\
\text { mentales del otro }\end{array}$} \\
\hline
\end{tabular}

Denota y/o explicita falta de certeza de los estados mentales del otro u otros

T: Terapeuta; P: Paciente

La dimensión OEM pudo observarse en la estructura del relato, ya sea por el uso de la primera persona singular, cada vez que se explicita el propio punto de vista y no "una realidad" a la que se alude (por ejemplo: P: "tal vez ellos lo ven distitno, pero yo siento que no se preocupan por mi"), o el uso de expresiones que evidencian una cualidad de duda sobre la experiencia interna del otro, tales como: "tal vez", "es posible que", entre otros. Un grado elevado de esta dimensión indica una actitud de curiosidad que motiva la elaboración de preguntas que a su vez favorecen una reflexión más profunda y precisa, pero no totalmente certera de la mente de otros, tal como se observa en la siguiente viñeta:

P: pienso que él se puede preocupar por mí porque vive conmigo, está todo el rato conmigo, - y con mis compañeros de curso también pensé que podía haber preocupación... por el tiempo que existe, porque pasamos mucho tiempo juntos. Pero acá es distinto o, a lo mejor, bueno ahora pensando puede ser que haya aún más preocupación desde usted conmigo porque como sabe todo lo que he vivido, entonces puede que exista un poco más de preocupación.

$\mathrm{T}$ : parece que hay una parte tuya que se pregunta ¿qué preocupación va a existir, qué lugar vas a ocupar tú, si voy a estar presente o no?

P: o sea igual siempre me preocupa; me he preguntado si a un psicólogo le importa lo que les pasa a sus pacientes porque igual es como contar todas mis cosas, igual es como raro.

La contraparte de la situación anterior se observó en interacciones que denotan certeza de lo que pasa en la mente de otros, sin base en el conocimiento previo, o bien, con base en "cómo son o deberían ser las cosas". Durante estos momentos, terapeutas y pacientes se posicionan como expertos en la experiencia de otros, lo que puede derivar en actitudes de control y escasa curiosidad. La siguiente viñeta da cuenta de este indicador en un paciente: 
T: hay que verlo, no sabemos todavía qué diría el psiquiatra.

$P$ : es que no quiero, o sea yo sé que me van a dar alguna estupidez, es obvio, porque no, no

T: ¿por cómo te estás sintiendo?

$P$ : no sé, o sea, me van a decir que soy depresivo y ya me van a pasar pastillas

T: ¿eso es lo que te da miedo?

$P$ : no es que en realidad no quiero saber lo que me pasa - no quiero saber (llora)

Comunicación contingente (CC)

Esta dimensión está basada en la comprensión de la psicoterapia como contexto dialógico de influencia mutua paciente-terapeuta, por el cual se espera una interacción colaborativa y emocionalmente sintónica en la que ambas partes intentan activamente trabajar juntas en la construcción de narrativas coherentes que permitan el avance de la terapia. En otras palabras, consiste en un sentido de conexión entre las propuestas de uno y respuestas del otro, que se deriva en un diálogo fluido y contextualizado que permite profundizar en la experiencia del adolescente (Ver Tabla 4).

Tabla 4. Dimensión de la mentalización: Comunicación contingente

\begin{tabular}{|c|c|c|c|}
\hline $\begin{array}{l}\text { Acciones del T } \\
\text { que promueven } \\
\text { mentalización del P }\end{array}$ & $\begin{array}{l}\text { Respuestas del } P \text { que } \\
\text { evidencian intento } \\
\text { por mentalizar en } \\
\text { respuesta al T }\end{array}$ & $\begin{array}{l}\text { Acciones del T que fallan } \\
\text { u obstaculizan promoción } \\
\text { de la mentalización del P }\end{array}$ & $\begin{array}{l}\text { Respuestas que } \\
\text { evidencian falla } \\
\text { en respuesta } \\
\text { mentalizadora del P }\end{array}$ \\
\hline \multicolumn{2}{|l|}{ Sintoniza con el afecto } & \multicolumn{2}{|l|}{ Impone su punto de vista } \\
\hline \multicolumn{2}{|c|}{ Sintoniza con el discurso } & \multicolumn{2}{|c|}{ Mantiene monólogo sin consideración del otro } \\
\hline \multicolumn{2}{|c|}{ Colaborativamente "sigue" al otro } & \multicolumn{2}{|c|}{$\begin{array}{l}\text { Mantiene un discurso demasiado abstracto o } \\
\text { experto que es poco comprensible para el otro }\end{array}$} \\
\hline & $\begin{array}{l}\text { Sigue pasivamente la } \\
\text { intervención del t }\end{array}$ & \multicolumn{2}{|c|}{$\begin{array}{l}\text { Cambia de tema de forma repentina a otro sin } \\
\text { conexión temática }\end{array}$} \\
\hline & & \multicolumn{2}{|c|}{$\begin{array}{l}\text { Interrumpe a su interlocutor como forma de } \\
\text { detener el diálogo reflexivo }\end{array}$} \\
\hline & & & $\begin{array}{l}\text { Evade propuesta } \\
\text { terapéutica }\end{array}$ \\
\hline
\end{tabular}

T: Terapeuta; P: Paciente

En los terapeutas, la CC se caracteriza por intervenciones en sintonía verbal y no verbal con el comportamiento, emoción y discurso del paciente. Se observó a partir de la consideración de elementos relevantes que el terapeuta transmite al adolescente y/o la explicitación de contenidos que, si bien no son expresados directa, lógica y plausiblemente pueden ser deducidos. Otro aspecto característico se advirtió en la formulación de intervenciones con un nivel de complejidad comprensible para el adolescente, vinculadas con intervenciones previas y en la posibilidad de adaptarse flexiblemente a cambios en la conversación con el fin de seguir el discurso del paciente.

La CC en los pacientes se observó cuando participaron colaborativamente, bien de forma activa, reflexionando a partir de las intervenciones del terapeuta, o bien pasiva, permaneciendo atentos a la interacción; y cuando expresaron manifestaron su acuerdo o desacuerdo con las propuestas del terapeuta a través de respuestas breves. 
$\mathrm{T}$ : ¿es algo como que lo que yo te pregunto es como que no me lo puedes explicar?

P: es que la verdad si supiera bien así yo estuviera segura, le podría explicar, pero como no estoy segura y estoy dando bote.

$\mathrm{T}$ : ¿así que sientes que estás dando bote con lo que te pregunto? (risa), ahora yo no, sí te puedo ayudar yo no espero que tengas las cosas claras, si no que en este conversar, para entender cómo te pasan las cosas

$P$ : es que con ella siempre pasa que es como enredado, porque siempre toma las cosas como de broma, entonces como ya han pasado cosas entre nosotras como que dije "no sé quizás puede que sea de verdad", pero por otra parte dije "no mejor no, no creo que sea cierto", y ahí empecé con la cosa.

Cuando los terapeutas no consideran la perspectiva del adolescente, imponen sus puntos de vista o no incorporan contenidos importantes que transmiten los pacientes, no se presenta CC; puede decirse que durante este tipo de intervenciones los terapeutas no son emocionalmente sintónicos. Ejemplos de esta situación son: cambios repentinos de tema, interrupciones, interpretaciones descontextualizadas, intervenciones excesivamente teóricas, irrelevantes, orientadas a criticar y/o con un nivel de complejidad difícil de entender para el paciente.

Por su parte, los pacientes demuestran baja CC cuando parecen no estar siguiendo o escuchando al terapeuta. Sus respuestas pueden ir desde la falta de correspondencia con las intervenciones de los terapeutas, pasando por cambios bruscos de tema, hasta evasivas o incluso claros intentos de control sobre el otro. Por otro lado, existe un tipo de respuestas que pueden ser "pseudocontingentes", en cuanto tienen un carácter más bien autoafirmativo, y, si bien podrían ser ejemplo de mentalización, dado su posicionamiento monológico, no están realmente orientadas a favorecer la construcción de un contexto de diálogo compartido.

T: Yo no te digo que no estudies, pero el tema que no tengas cuaderno y aun así te vaya bien. 0 sea, si tú tomaras apuntes tu rendimiento subiría aún más

$P$ : Es que para que voy a tomar apuntes si no los voy a leer

$\mathrm{T}$ : Te lo digo como ejemplo de las capacidades que tienes y las hagas conscientes y que puedas explotarlas de esa manera.

$P: Y$ además como que nos pasan puros PPTs y después los mandan, así que para que voy a prestar atención, mejor duermo

T: Claro, pero ese tiempo que después es libre lo gastas estudiando porque en clases duermes. Para eso son las clases, para ahorrarte tiempo y después cuando salgas del colegio, qué sé yo, puedas estudiar un poco, pero también dedicarte a otras cosas

$P$ : No.

Naturaleza dinámica de los estados mentales (NDEM)

Esta dimensión caracteriza intervenciones que evidencian un reconocimiento de la complejidad de los estados mentales a partir de discursos que, explícita o implícitamente, hacen referencia a que no hay una sola versión de un estado mental particular, o bien, éstos no son estáticos (Ver Tabla 5). 
Tabla 5. Dimensión de la mentalización: Naturaleza dinámica de los estados mentales

\begin{tabular}{llll}
\hline $\begin{array}{l}\text { Acciones del T } \\
\text { que promueven } \\
\text { mentalización del P }\end{array}$ & $\begin{array}{l}\text { Respuestas del P que } \\
\text { evidencian intento por } \\
\text { al T }\end{array}$ & $\begin{array}{l}\text { Acciones del T que } \\
\text { fallan u obstaculizan en respuesta } \\
\text { promoción de la } \\
\text { mentalización del P }\end{array}$ & $\begin{array}{l}\text { Respuestas que } \\
\text { evidencian falla } \\
\text { en respuesta } \\
\text { mentalizadora del P }\end{array}$ \\
\hline $\begin{array}{l}\text { Considera posibilidad de existencia de distintos } \\
\text { puntos de vista }\end{array}$ & $\begin{array}{l}\text { No considera NDEM } \\
\text { frente a claras } \\
\text { oportunidades de } \\
\text { hacerlo }\end{array}$ & $\begin{array}{l}\text { No considera NDEM } \\
\text { cuando se le demanda } \\
\text { hacerlo }\end{array}$ \\
\hline $\begin{array}{l}\text { Reconoce, tolera y/o integra contradicciones } \\
\text { en EM }\end{array}$ & $\begin{array}{l}\text { Utiliza NDEM para } \\
\text { imponer ideas }\end{array}$ & $\begin{array}{l}\text { Incorpora NDEM de } \\
\text { forma utilitaria }\end{array}$ \\
\hline $\begin{array}{l}\text { Aborda naturaleza cambiante de los EM en el } \\
\text { tiempo }\end{array}$ & & \\
\hline $\begin{array}{l}\text { Refiere la posibilidad de modificar EM a } \\
\text { voluntad (por ej. ocultarlos, regularlos) }\end{array}$ & & \\
\hline T: Terapeuta; P: Paciente & & \\
\hline
\end{tabular}

La dimensión NDEM se observa a través de interacciones que evidencian discursivamente: a) la existencia de diferentes puntos de vista ("yo estaba triste, pero creo que ellos pensaron que no me pasaba nada"); b) la capacidad de reconocer, tolerar e integrar contradicciones de estados mentales, lo que también incluye el reconocimiento de emociones mezcladas ("eso es, por un lado, pero, por otro lado, cuando aparece ese tema parece que sí preocupa. En teoría no te preocupa, pero en la práctica parece que sí"); y c) el reconocimiento de la naturaleza cambiante de los afectos y cogniciones ya sea por el paso del tiempo ("en general, cuando llegaste con este motivo de consulta ¿te acuerdas un poco, de cómo llegaste, porque eras otra Sandra de lo que estoy viendo ahora ¿no?, mucho más callada. ¿Cómo te sentías en ese entonces? ¿Cómo te puedes sentir ahora?") o bien, por la posibilidad de manipularlos a voluntad, y así, por ejemplo, poder ocultarlos o regularlos ("es que es como... como que al tocar el tema de mi expareja polola² igual es como algo súper como principal en mí entonces es como que me acuerdo y como que veo el espejo y como que omito cosas, igual lo digo, pero que cuando lo digo como ya estaba olvidándome").

Fallas en el proceso de mentalizar en esta dimensión se observan, en el caso de los terapeutas, cuando éstos pierden la oportunidad de promover el reconocimiento de la complejidad de los estados mentales del paciente, recurren a la NDEM a modo de cliché ("bueno, así son las cosas, siempre hay gente que piensa distinto") o bien, para imponer ideas personales, más que promover la mentalización del adolescente.

En los pacientes, estas dificultades se observan cuando omiten el uso de esta dimensión frente a intervenciones terapéuticas que lo demandan, o bien, incorporan en el discurso elementos propios de la NDEM de manera antinatural y poco consistente emocionalmente, dando la impresión de realizar una acción con un fin utilitario, como tratar de convencer al terapeuta, ser condescendiente, o "salir del paso".

Causalidad de los estados mentales (CEM)

Esta dimensión corresponde a intervenciones que implícita o explícitamente consideran, de manera coherente y plausible, las múltiples formas en que las conductas, afectos y cogniciones de uno mismo y otros pueden verse mutuamente influidos, o bien, tener efecto o verse afectados por dinámicas relacionales (Ver Tabla 6).

2. Persona que mantiene con otra una relación amorosa que no alcanza, en nivel de compromiso, a la del noviazgo (Definiciones de Oxford Languages). 
Tabla 6. Dimensión de la mentalización: Causalidad de los estados mentales

\begin{tabular}{llll}
\hline $\begin{array}{l}\text { Acciones del T } \\
\text { que promueven } \\
\text { mentalización del P }\end{array}$ & $\begin{array}{l}\text { Respuestas del P que } \\
\text { evidencian intento } \\
\text { por mentalizar en } \\
\text { respuesta al T }\end{array}$ & $\begin{array}{l}\text { Acciones del T que fallan } \\
\text { u obstaculizan promoción } \\
\text { de la mentalización del P }\end{array}$ & $\begin{array}{l}\text { Respuestas que } \\
\text { evidencian falla } \\
\text { en respuesta } \\
\text { mentalizadora del P }\end{array}$ \\
\hline Refiere influencia EM-EM & $\begin{array}{l}\text { No considera CEM frente } \\
\text { a claras oportunidades de } \\
\text { hacerlo }\end{array}$ & $\begin{array}{l}\text { No considera } \\
\text { CEM cuando se le } \\
\text { demanda hacerlo }\end{array}$ \\
\hline $\begin{array}{l}\text { Refiere influencia EM-Dinámicas } \\
\text { relacionales }\end{array}$ & $\begin{array}{l}\text { Utiliza CEM para imponer } \\
\text { ideas }\end{array}$ & $\begin{array}{l}\text { Incorpora CEM de } \\
\text { forma utilitaria }\end{array}$ \\
\hline Refiere influencia EM-Conducta & & \\
\hline T: Terapeuta; P: Paciente & &
\end{tabular}

Esta dimensión puede observarse en la siguiente viñeta:

T: ¿qué es lo que te desagrada de la nueva pareja de tu papá?

$P$ : todo

T: pero algo debe ser en particular más complejo, porque tú incluso antes de conocerla ya tenías como con una predisposición negativa hacia ella. $P$ : es que era lo mismo que me pasaba con mi papá, que no me gustaba verlos bien porque sabía que iban a pelear después.

Las fallas en el proceso de mentalización en esta dimensión, tanto para terapeutas como para pacientes, cumplen los mismos criterios que la dimensión de la NDEM, es decir, cuando se omiten respuestas a intervenciones terapéuticas que lo demandan o se utiliza de manera antinatural y poco consistente emocionalmente.

Foco en el momento presente (FMP)

Esta dimensión describe verbalizaciones y/o manifestaciones no verbales que se focalizan, o promueven la focalización, en el aquí y el ahora (Ver Tabla 7).

Tabla 7. Dimensión de la mentalización: Foco en el momento presente

\begin{tabular}{llll}
\hline $\begin{array}{l}\text { Acciones del T } \\
\text { que promueven } \\
\text { mentalización del P }\end{array}$ & $\begin{array}{l}\text { Respuestas del P que } \\
\text { evidencian intento por } \\
\text { mentalizar en respuesta } \\
\text { al T }\end{array}$ & $\begin{array}{l}\text { Acciones del T que } \\
\text { fallan u obstaculizan } \\
\text { promoción de la } \\
\text { mentalización del P }\end{array}$ & $\begin{array}{l}\text { Respuestas que } \\
\text { evidencian falla } \\
\text { en respuesta } \\
\text { mentalizadora del P }\end{array}$ \\
\hline $\begin{array}{l}\text { Demuestra intención } \\
\text { por que se focalice } \\
\text { la conversación en el intentos por } \\
\text { presente }\end{array}$ & $\begin{array}{l}\text { Hace } \\
\text { regular afectos } \\
\text { conectados con } \\
\text { situaciones pasadas o } \\
\text { futuras }\end{array}$ & $\begin{array}{l}\text { Promueve la } \\
\text { desregulación afectiva } \\
\text { del otro o evidencia } \\
\text { desregulación emocional }\end{array}$ & $\begin{array}{l}\text { Evidencia } \\
\text { desregulación } \\
\text { emocional }\end{array}$ \\
\hline & & $\begin{array}{l}\text { Promueve o mantiene } \\
\text { estancamiento del P en } \\
\text { el pasado o futuro }\end{array}$ & $\begin{array}{l}\text { Se estanca en el } \\
\text { discurso sobre } \\
\text { situaciones pasadas } \\
\text { o futuras }\end{array}$ \\
\hline
\end{tabular}

T: Terapeuta; P: Paciente 
La dimensión FMP se observa a través del uso del tiempo verbal presente ("ahora que lo pienso...", "eso me hace sentir..."), o bien, como invitación directa a focalizarse en el presente; algo que suele ser más característico del rol que asumen los terapeutas. No obstante, la mera mención del tiempo presente no es condición suficiente; diversas intervenciones se caracterizan por revisar experiencias pasadas o expectativas, sin embargo, sólo son consideradas como indicios de FMP cuando tienen la cualidad de centrarse en estos eventos, sin perder el posicionamiento en la experiencia presente e inmediata. La capacidad de los terapeutas para regular el afecto o la intención por resguardar esta capacidad en el adolescente a través de acciones que, por ejemplo, detienen reflexiones que los estancan en el pasado o en el futuro, es un criterio no verbal que conforma esta dimensión. En el caso de los pacientes, la cualidad del discurso focalizado en el aquí y el ahora puede llegar a transmitir, tal como en la siguiente viñeta, una sensación de estar espontánea y vívidamente conectado con emociones y pensamientos en el presente.

T: eso es algo que te da mucha pena pensarlo... porque todos al mismo tiempo dependemos de gente alrededor de alguna manera en mayor o menor medida

$P:$ sí, pero "pucha" si la gente no está, tampoco la voy a andar buscando

$\mathrm{T}$ : qué te pasa con esa idea de la soledad donde la gente no esté o que no hay que ilusionarse o tener que estar demasiado cerca

$P$ : me da pena en realidad o sea es que (llora)

T: porque hay que trabajar eso... esa distancia aquí es algo complicado encuentro yo, ¿o no?, porque éste es un espacio íntimo por definición.

Un nivel bajo de la dimensión FMP se observa en los terapeutas cuando realizan acciones que promueven el estancamiento o la desregulación afectiva, o cuando responden pasivamente a interacciones que evidencian un foco fuera del aquí y el ahora.

En el caso de los adolescentes, un bajo nivel de FMP se observa en situaciones en las que se desbordan emocionalmente, y esto interfiere en su capacidad de reflexionar sobre sus propios estados o en momentos de estancamiento del proceso terapéutico. También en respuestas que tienen la cualidad de ser automáticas, que dan la sensación de rechazo al momento presente; por ejemplo, cuando se expresan con monosílabos. Otro ejemplo de este mismo tipo de respuestas corresponde a discursos autoafirmativos en los que el adolescente pareciera estar convenciendo al terapeuta de un punto de vista o de la veracidad de su experiencia.

La siguiente viñeta ejemplifica un bajo nivel de FMP en ambos actores. Previamente, el terapeuta lleva a cabo una extensa intervención en la que analiza el motivo de consulta del adolescente. Éste se muestra inicialmente atento, pero a medida que el terapeuta profundiza en el análisis, parece cada vez más ansioso, retrayéndose de la interacción. Esto parece no advertirlo el terapeuta, quien mantiene su intervención. Al concluir, se aprecia que el paciente no logró atender lo planteado por el clínico.

T: no sé qué opinas de este monólogo

$P$ : si (le tiembla la voz)

T: ¿sí señor? ¿sí, juro? (bromeando) .... qué piensas pues

$P$ : qué... puede ser... digo... o sea.... no opino mucho. 
Se identificaron indicadores de la mentalización que pueden ser observados mientras transcurre la psicoterapia. Este hallazgo representa un importante avance para la investigación en psicoterapia con adolescentes, ya que hasta el momento no se cuenta con medidas que logren captar elementos dinámicos y contextuales del proceso de mentalización en psicoterapia.

\section{Sistema de observación “Observando la mentalización en Psicoterapia con ado- lescentes"}

A partir de las dimensiones emergentes descritas en el subapartado anterior, se generó, tal como fue descrito en la metodología, una rúbrica para la evaluación cuantitativa de la mentalización de terapeutas y pacientes en la interacción terapéutica (Ver Anexo 1). Es importante destacar que este instrumento, en su versión piloto, ha sido diseñado para ser utilizado a partir de material videograbado y transcrito de una psicoterapia, dado que requiere de la observación de aspectos tanto discursivos explícitos como paraverbales; el mismo método que se siguió para su desarrollo.

\section{Discusión}

El presente estudio tuvo como objetivo presentar el diseño y desarrollo del OMP-A, un sistema de observación de la mentalización en el proceso psicoterapéutico con adolescentes. Si bien se presenta como una versión piloto, el estudio entrega resultados alentadores que se destacan a continuación.

En primer lugar, se identificaron indicadores de la mentalización que pueden ser observados mientras transcurre la psicoterapia. Este hallazgo representa un importante avance para la investigación en psicoterapia con adolescentes, ya que hasta el momento no se cuenta con medidas que logren captar elementos dinámicos y contextuales del proceso de mentalización en psicoterapia.

Un segundo aspecto relevante, es la posibilidad que ofrece el OMP-A para evaluar tanto aspectos lingüísticos como paralingüísticos de la mentalización. Si bien, no se desconoce el aporte de la escala de Función Reflexiva para la evaluación de la mentalización explícita EFR, varios investigadores han llamado la atención sobre la multidimensionalidad del concepto de mentalización (Choi-Kain \& Gunderson, 2008; Luyten, Fonagy, Lowyck \& Vermote, 2012) y la necesidad de acceder a aspectos preverbales e implícitos que caracterizan este sistema intersubjetivo de enlace social (Cortina \& Liotti, 2010; Liljenfors \& Lundh, 2015). Así, las dimensiones "FEM", "CEM" y "NDEM" del sistema OMP-A evalúan de forma más directa aspectos discursivos-explícitos de la interacción terapéutica, los que en su mayoría también son recogidos por la EFR. Mientras que la dimensión "CC" del OMP-A se focaliza sobre aspectos paralingüísticos, y las dimensiones "OEM" y "FMP" abordan aspectos tanto explícitos como implícitos de la mentalización en psicoterapia. De ahí, la importancia y la necesidad de continuar explorando los alcances y capacidades del instrumento para evaluar la mentalización implícita.

En tercer lugar, el OMP-A es adecuado para captar aspectos de las interacciones terapéuticas típicas con adolescentes; es decir, aquellas en las que no se mencionan explícitamente los estados mentales, ya sea por falta de colaboración, menor desarrollo del lenguaje o, bien, el uso de jergas propias de los jóvenes.

Además, es de especial relevancia el potencial de este instrumento para identificar y analizar la emergencia de modos no mentalizadores descritos en la literatura (i.e. "modo como si", "modo teleológico", "equivalencia psíquica" (Bateman \& Fonagy, 2004)). 
El sistema OMP-A permite evaluar la mentalización como fenómeno interactivo en la relación entre terapeutas y sus pacientes. Evaluar la contribución de ambos sujetos para el despliegue de la mentalización de manera dinámica es un aporte significativo, pues abre posibilidades no sólo a la investigación, sino que también a su uso en contextos clínicos y en espacios de formación y supervisión en psicoterapia; y para la evaluación del desarrollo de competencias terapéuticas en intervenciones basadas en la mentalización.
Finalmente, el sistema OMP-A permite evaluar la mentalización como fenómeno interactivo en la relación entre terapeutas y sus pacientes. Evaluar la contribución de ambos sujetos para el despliegue de la mentalización de manera dinámica es un aporte significativo, pues abre posibilidades no sólo a la investigación, sino que también a su uso en contextos clínicos y en espacios de formación y supervisión en psicoterapia; y para la evaluación del desarrollo de competencias terapéuticas en intervenciones basadas en la mentalización.

Pese a los resultados prometedores, este estudio tiene limitaciones importantes, tales como el bajo número de terapias analizadas y la homogeneidad en el diagnóstico de los participantes. Adicionalmente, es necesario llevar a cabo un estudio que evalúe características psicométricas del OMP-A, tales como confiabilidad entre evaluadores independientes, y especialmente un estudio de validez convergente mediante un gold standard. Así también, resulta necesario manualizar aspectos ligados al uso del instrumento que aseguren un entrenamiento uniforme para los codificadores.

Parte importante de estos desafíos está siendo abordada por el equipo de investigadores encargado del diseño de este instrumento y se espera contar prontamente con evidencia cuantitativa que dé cuenta de la aplicabilidad del sistema OMP-A.

\section{Referencias}

Allen, J. \& Fonagy, P. (2006). Handbook of mentalization-based treatment. J.G. Allen \& P. Fonagy (Eds.), New York: Wiley.

Asen, E., \& Fonagy, P. (2012). Mentalization-based therapeutic interventions for families. Journal of Family Therapy, 34(4), 347-370. https://doi.org/10.1111/j.1467$\underline{6427.2011 .00552 . x}$

Bateman, A. W., \& Fonagy, P. (2004). Mentalization-based treatment of BPD. Journal of personality disorders, 18(1), 36-51. https://psycnet.apa.org/doi/10.1521/ pedi.18.1.36.32772

Bateman, A., Peter (Psychoanalysis Unit Fonagy, \& Fonagy, P. (2004). Psychotherapy for borderline personality disorder. Oxford: Oxford University Press.

Bateman, A., \& Fonagy, P. (2006). Mentalization-based treatment for personality disorders: A practical guide. Reino Unido: Oxford University Press.

Bateman, A. W., \& Fonagy, P. (Eds.). (2012). Handbook of mentalizing in mental health practice. London: American Psychiatric Association Publishing.

Bateman, A. W., \& Fonagy, P. (Eds). (2019). Handbook of mentalizing in mental health practice. London: American Psychiatric Association Publishing.

Bevington, D., Fuggle, P., Fonagy, P., Target, M., \& Asen, E. (2013) Innovations in Practice: Adolescent Mentalization-Based Integrative Therapy (AMBIT). Child and Adolescent Mental Health, 18 (1), 46 - 51. https://doi.org/10.1111/j.14753588.2012.00666.x

Binder, P. E., Holgersen, H., \& Nielsen, G. H. (2008). Establishing a bond that works: A qualitative study of how psychotherapists make contact with adolescent patients. European Journal of psychotherapy and counselling, 10(1), 55-69. https:// doi.org/10.1080/13642530701869730

Bleiberg E., Rossouw T., \& Fonagy P. (2012). Adolescent breakdown and emerging personality disorder. In Bateman AW, Fonagy P (eds). Handbook of mentalizing in mental health practice (p. 463-509). Washington, DC: American Psychiatric Publishing. 
Bo, S., Sharp, C., Beck, E., Pedersen, J., Gondan, M., \& Simonsen, E. (2017). First empirical evaluation of outcomes for mentalization-based group therapy for adolescents with BPD. Personality Disorders: Theory, Research, and Treatment, 8(4), 396. https://psycnet.apa.org/doi/10.1037/per0000210

Charmaz, K. (2014). Constructing grounded theory. A practical guide through qualitative analysis (2nd ed.). Thousand Oaks, CA: Sage

Choi-Kain, L., \& Gunderson, J. (2008). Mentalization: Ontogeny, assessment and application in the treatment of borderline personality disorder. Am J Psychiatry, 165(9): 1127-1135. https://doi.org/10.1037/per0000210

Cortina, M., Liotti, G., \& Silberman, M. (2012). Cooperación, intersubjetividad y apego. Aperturas Psicoanalíticas, 41. http://www.aperturas.org/articulo.php?articu$\underline{\text { lo }=0000750}$

De la Cerda, C., Martínez, C., \& Tomicic, A. (2018). La función reflexiva como aprendizaje procedural en la interacción terapéutica: el funcionamiento reflexivo-relacional. Revista Argentina de Clínica Psicológica, 28(3), 285-294. http://doi. org/10.24205/03276716.2019.1142

Dziobek, I., Fleck, S., Kalbe, E., Rogers, K., Hassenstab, J., Brand, M., ... Convit, A. (2006). Introducing MASC: a movie for the assessment of social cognition. Journal of autism and developmental disorders, 36(5), 623-636. https://doi.org/10.1007/ s10803-006-0107-0

Eubanks-Carter, C., Muran, J. C., \& Safran, J. D. (2014). Rupture resolution rating system (3RS): Manual. Unpublished manuscript, Beth Israel Medical Center, New York.

Fischer-Kern, M., Doering, S., Taubner, S., Hörz, S., Zimmermann, J., Rentrop, M., ... Buchheim, A. (2015). Transference-focused psychotherapy for borderline personality disorder: Change in reflective function. The British Journal of Psychiatry, 207(2), 173-174. https://doi.org/10.1192/bjp.bp.113.143842

Flick, U. (2009). An introduction to qualitative research (4th ed.). London: Sage

Frith, U., \& Frith, C. D. (2003). Development and neurophysiology of mentalizing. Philosophical Transactions of the Royal Society London, Series B, 358, 685-694. https:// doi.org/10.1098/rstb.2002.1218

Fonagy, P., Target, M., Steele, H., \& Steele, M. (1998). Reflective-Functioning Manuel, version 5.0, for Application to Adult Attachment Interviews. London: University College London.

Fonagy, P., Gergely, G., Jurist, E. L., \& Target, M. (Eds.). (2002). Affect regulation, mentalization and the development of the self. New York: Other Press.

Gensler, D. (2015). Silence in adolescent psychotherapy. Journal of Infant, Child, and Adolescent Psychotherapy, 14(2), 188-195. https://doi.org/10.1080/15289168.20 15.1032635

Gullestad, F. S., \& Wilberg, T. (2011). Change in reflective functioning during psychotherapy-A single-case study. Psychotherapy Research, 21(1), 97-111. https:// doi.org/10.1080/10503307.2010.525759

Gullestad, F. S., Johansen, M. S., Høglend, P., Karterud, S., \& Wilberg, T. (2013). Mentalization as a moderator of treatment effects: Findings from a randomized clinical trial for personality disorders. Psychotherapy Research, 23(6), 674-689. https:// doi.org/10.1080/10503307.2012.684103

Hauser, S. T., Allen, J. P., \& Golden, E. (2006). Out of the woods: Tales of teen resilience. Cambride: Harvard University Press.

Hörz-Sagstetter, S., Mertens, W., Isphording, S., Buchheim, A., \& Taubner, S. (2015). Changes in Reflective Functioning during Psychoanalytic Psychotherapies. Journal of the American Psychoanalytic Association, 63(3), 481-509. https://doi. org/10.1177\%2F0003065115591977 
Katznelson, H. (2014). Reflective functioning: A review. Clinical psychology review, 34(2), 107-117. https://doi.org/10.1016/j.cpr.2013.12.003

Koo, T. K., \& Li, M. Y. (2016). A guideline of selecting and reporting intraclass correlation coefficients for reliability research. Journal of chiropractic medicine, 15(2), 155-163. https://doi.org/10.1016/j.jcm.2016.02.012

Levy, K. N., Meehan, K. B., Kelly, K. M., Reynoso, J. S., Weber, M., Clarkin, J. F., \& Kernberg, 0. F. (2006). Change in attachment patterns and reflective function in a randomized control trial of transference-focused psychotherapy for borderline personality disorder. Journal of consulting and clinical psychology, 74(6), 1027-1040. https:// doi.apa.org/doi/10.1037/0022-006X.74.6.1027

Liljenfors, R., \& Lundh, L. G. (2015). Mentalization and intersubjectivity towards a theoretical integration. Psychoanalytic Psychology, 32(1), 36-60 https://doi.apa. org/doi/10.1037/a0037129

Lingiardi, V., \& Colli, A. (2015). Therapeutic Alliance and Alliance Ruptures and Resolutions: Theoretical Definitions, Assessment Issues, and Research Findings. En O. Gelo, A. Pritz, \& B. Rieken (Eds.), Psychotherapy Research: Foundations, Process and outcome. London: Springer.

Luyten, P., Fonagy, P., Lowyck, B., \& Vermote, R. (2012). Assessment of mentalization. In A. W. Bateman, \& P. Fonagy (Eds.), Handbook of mentalizing in mental health practice (pp. 43-65). Arlington, VA, US: American Psychiatric Publishing, Inc.

Main, M., Goldwyn, R., \& Hesse, E. (2003). The Adult Attachment Interview: Scoring and Classification System, Version 7.2. Unpublished manuscript, University of California at Berkeley.

Martínez, C. M., Tomicic, A., De la Cerda, C., Rivera, M. J., \& Salas, C. (2017). Función Reflexiva en Primeras Entrevistas de Psicoterapia: Un Estudio Exploratorio sobre el Papel de la Mentalización en la Interacción Terapéutica. Revista Argentina de Clínica Psicológica, 26(3), 274-282. https://doi. org/10.24205/03276716.2017.1026

McLeod, B. D., Jensen-Doss, A., Tully, C. B., Southam-Gerow, M. A., Weisz, J. R., \& Kendall, P. C. (2016). The role of setting versus treatment type in alliance within youth therapy. Journal of consulting and clinical psychology, 84(5), 453-464. https://doi. apa.org/doi/10.1037/ccp0000081

Magill-Evans, J., Koning, C., Cameron-Sadava, A., \& Manyk, K. (1995). The child and adolescent social perception measure. Journal of Nonverbal Behavior, 19(3), 151 169. https://doi.org/10.1007/BF02175502

Meins, E., Fernyhough, C., de Rosnay, M., Arnott, B., Leekam, S. R., \& Turner, M. (2012). Mind-mindedness as a multidimensional construct: Appropriate and nonattuned mind-related comments independently predict infant-mother attachment in a socially diverse sample. Infancy, 17(4), 393-415. https://doi.org/10.1111/j.15327078.2011.00087.x

Morán, J., Díaz, M. F., Martínez, C., Varas, C., \& Sepúlveda, R. P. (2019). The subjective experience of psychotherapists during moments of rupture in psychotherapy with adolescents. Research in Psychotherapy: Psychopathology, Process and Outcome, 22(1). https://doi.org/10.4081/ripppo.2019.346

Morken, K., Karterud, S., \& Arefjord, N. (2014). Transforming disorganized attachment through mentalization-based treatment. Journal of Contemporary Psychotherapy, 44(2), 117-126 https://doi.org/10.1007/s10879-013-9246-8

Rossouw, T. I., \& Fonagy, P. (2012). Mentalization-based treatment for self-harm in adolescents: a randomized controlled trial. Journal of the American Academy of Child \& Adolescent Psychiatry, 51(12), 1304-1313. https://doi.org/10.1016/j. jaac. 2012.09.018 
Rossouw, T. I. (2015). The Use of Mentalization-Based Treatment for Adolescents (MBT-A) With a Young Woman with Mixed Personality Disorder and Tendencies to Self-Harm. Journal of clinical psychology, 71(2), 178-187. https://doi. org/10.1016/j.jaac.2012.09.018

Ruffman, T., Slade, L., \& Crowe, E. (2002). The relation between children's and mother's mental state language and theory of mind understanding. Child development, 73(3), 734-751. https://doi.org/10.1111/1467-8624.00435

Safran, J. D., \& Muran, J. C. (1996). The resolution of ruptures in the therapeutic alliance. Journal of consulting and clinical psychology, 64(3), 447. https://doi.apa.org/ doi/10.1037/0022-006X.64.3.447

Safran, J. D., \& Muran, J. C. (2005). La alianza terapéutica. Una guía para el tratamiento relacional. Bilbao: Desclée de Brouwer.

Talia, A., Miller-Bottome, M., Katznelson, H., Pedersen, S. H., Steele, H., Schröder, P., ... Lingiardi, V. (2019). Mentalizing in the presence of another: Measuring reflective functioning and attachment in the therapy process. Psychotherapy Research, 29(5), 652-665. https://doi.org/10.1080/10503307.2017.1417651

Tobin, G. A., \& Begley, C. M. (2004). Methodological rigour within a qualitative framework. Journal of advanced nursing, 48(4), 388-396. https://doi.org/10.1111/ j.1365-2648.2004.03207.x

Schore, J., \& Schore, A. (2007). Modern Attachment Theory: A Central Role of Affect Regulation in Development and Treatment. Clinical Social Work Journal, 36(1), 9-20. https://doi.org/10.1007/s10615-007-0111-7

Sharp, C., \& Fonagy, P. (2008). The parent "s capacity to treat the child as a psychological agent: Constructs, measures and implications for developmental psychopathology. Social Development, 17(3), 737-754. https://doi.org/10.1111/j.14679507.2007.00457.x

Sharp, C., \& Fonagy, P. (2015). Practitioner review: borderline personality disorder in adolescence-recent conceptualization, intervention, and implications for clinical practice. Journal of Child Psychology and Psychiatry, 56(12), 1266-1288. https:// doi.org/10.1111/icpp.12449

Spunt, R. P., Satpute, A. B., \& Lieberman, M. D. (2011). Identifying the what, why, and how of an observed action: an fMRI study of mentalizing and mechanizing during action observation. Journal of cognitive neuroscience, 23(1), 63-74. https://doi. org/10.1162/jocn.2010.21446

Valdés, C., Morales-Reyes, I., Pérez, J. C., Medellín, A., Rojas, G., \& Krause, M. (2017) Propiedades psicométricas del Inventario de Depresión de Beck IA para la población chilena. Revista médica de Chile, 145(8), 1005-1012. http://dx.doi. org/10.4067/s0034-98872017000801005

Vrouva, I., Target, M., \& Ensink, K. (2013). Measuring mentalization in children and young people. In Minding the Child (pp. 68-90). Routledge. 


\section{Anexo 1}

Sistema de Observación de la Mentalización en Psicoterapia con Adolescentes (OMP-A)

\begin{tabular}{|c|c|c|c|c|c|}
\hline \multicolumn{6}{|c|}{ 1. Foco en los estados mentales } \\
\hline & 1 & 2 & 3 & 4 & 5 \\
\hline 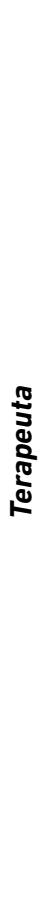 & $\begin{array}{l}\text { El T está casi } \\
\text { exclusivamente } \\
\text { focalizado en } \\
\text { aspectos externos } \\
\text { y observables tales } \\
\text { como la conducta o } \\
\text { eventos concretos, } \\
\text { de tal forma que } \\
\text { los EM no están } \\
\text { considerados. } \\
\text { Cuando el discurso } \\
\text { del P es automático } \\
\text { o utiliza clichés, el T } \\
\text { parece no advertirlo. } \\
\text { Como resultado, } \\
\text { se pierden } \\
\text { oportunidades } \\
\text { importantes para } \\
\text { favorecer el uso de } \\
\text { EM en el P. }\end{array}$ & $\begin{array}{l}\text { EM son mencionados, } \\
\text { pero no están claramente } \\
\text { ligados al comportamiento } \\
\text { presente o pasado. } \\
\text { Como resultado, las } \\
\text { intervenciones del T no } \\
\text { parecen promover el } \\
\text { funcionamiento reflexivo } \\
\text { en el P. El T puede asumir } \\
\text { una actitud pasiva } \\
\text { (silente/distante) o estar } \\
\text { demasiado focalizado } \\
\text { en aspectos externos } \\
\text { como para permitir una } \\
\text { completa inclusión de } \\
\text { los EM cuando éstos son } \\
\text { mencionados. Tal como en } \\
\text { el caso anterior (1 punto), } \\
\text { cuando el discurso del P } \\
\text { es automático o utiliza } \\
\text { clichés, el T se mantiene } \\
\text { pasivo. }\end{array}$ & $\begin{array}{l}\text { Promover el uso de } \\
\text { EM en el P puede } \\
\text { ser considerado } \\
\text { como parte de la } \\
\text { intervención, sin } \\
\text { embargo, éstos } \\
\text { no parecen ser el } \\
\text { principal foco. Como } \\
\text { resultado, el uso de } \\
\text { EM se promueve de } \\
\text { manera parcial en } \\
\text { el P, perdiéndose } \\
\text { importantes } \\
\text { oportunidades de } \\
\text { favorecer su uso de } \\
\text { una forma profunda. } \\
\text { Cuando el discurso } \\
\text { del P es automático } \\
\text { o utiliza clichés, éste } \\
\text { no se detiene. }\end{array}$ & $\begin{array}{l}\text { La mayoría de las } \\
\text { intervenciones están } \\
\text { claramente orientadas a } \\
\text { promover el uso de los } \\
\text { EM en el P. El T realiza } \\
\text { intervenciones que } \\
\text { "demandan" reflexionar } \\
\text { sobre cogniciones, } \\
\text { creencias y afectos, } \\
\text { sentimientos, deseos, o } \\
\text { bien, detienen discursos } \\
\text { automáticos y/o clichés } \\
\text { de su P. Como resultado, } \\
\text { la intervención podría } \\
\text { promover significativamente } \\
\text { la reflexión en el P. Puntúe } \\
\text { también como } 4 \text { situaciones } \\
\text { en que, si bien los EM no han } \\
\text { sido el foco principal, existe } \\
\text { al menos una intervención } \\
\text { que es de suma relevancia } \\
\text { para el sentido del segmento } \\
\text { donde se promueve el uso } \\
\text { de EM de forma significativa. }\end{array}$ & $\begin{array}{l}\text { El T puede ser } \\
\text { claramente descrito } \\
\text { como activamente } \\
\text { promoviendo el } \\
\text { uso de EM en el P, } \\
\text { elaborando preguntas } \\
\text { y/o intervenciones que } \\
\text { demandan reflexionar } \\
\text { sobre cogniciones/ } \\
\text { creencias y afectos/ } \\
\text { sentimientos/deseos y } \\
\text { deteniendo discursos } \\
\text { automáticos y/o } \\
\text { clichés. Eventos y } \\
\text { situaciones pueden } \\
\text { ser integrados } \\
\text { como un importante } \\
\text { complemento que } \\
\text { enriquece la reflexión. } \\
\text { Como resultado, la } \\
\text { intervención podría } \\
\text { promover significativa } \\
\text { y profundamente la } \\
\text { reflexión en el P. }\end{array}$ \\
\hline 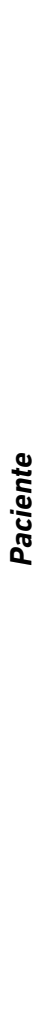 & $\begin{array}{l}\text { El discurso } \\
\text { del P está } \\
\text { predominantemente } \\
\text { focalizado en el } \\
\text { comportamiento, } \\
\text { acciones y/o en } \\
\text { la descripción de } \\
\text { eventos, sin hacer } \\
\text { referencia clara y/o } \\
\text { explícita a EM. Si se } \\
\text { hacen preguntas de } \\
\text { demanda, el foco } \\
\text { sobre aspectos } \\
\text { externos se } \\
\text { mantiene. }\end{array}$ & $\begin{array}{l}\text { Los EM son considerados } \\
\text { de manera circunstancial, } \\
\text { no como un aspecto } \\
\text { relevante del sentido del } \\
\text { discurso del P. El foco } \\
\text { principal del P se orienta } \\
\text { a describir acciones } \\
\text { observables y eventos } \\
\text { en vez de reflexionar } \\
\text { sobre cogniciones y } \\
\text { afectos Si se realizan } \\
\text { preguntas de demanda } \\
\text { los EM continúan siendo } \\
\text { circunstancialmente } \\
\text { usados. Igualmente se } \\
\text { codifica con } 2 \text { puntos } \\
\text { situaciones en que existe } \\
\text { mención de EM, pero } \\
\text { a partir de la conducta } \\
\text { no verbal no es posible } \\
\text { determinar si realmente } \\
\text { el P está reflexionando. } \\
\text { Existen ocasiones en que } \\
\text { parece haber uso de EM, } \\
\text { pero estos se incorporan } \\
\text { al discurso de manera } \\
\text { automática y/o cliché. }\end{array}$ & $\begin{array}{l}\text { Los EM son } \\
\text { considerados en } \\
\text { el discurso del P, } \\
\text { pero no como su } \\
\text { foco principal. De } \\
\text { esta forma, pese } \\
\text { a la presencia de } \\
\text { descripciones sobre } \\
\text { eventos externos } \\
\text { y conductas } \\
\text { observables, es } \\
\text { posible identificar } \\
\text { procesos reflexivos. } \\
\text { Es posible observar } \\
\text { la inclusión de } \\
\text { algunos clichés o } \\
\text { ideas automáticas, } \\
\text { las que se integran a } \\
\text { la reflexión. }\end{array}$ & $\begin{array}{l}\text { El discurso del P está } \\
\text { predominantemente } \\
\text { focalizado en EM, los que } \\
\text { son claramente usados } \\
\text { para reflexionar, por sobre } \\
\text { una mera descripción } \\
\text { de eventos externos y } \\
\text { conductas observables. } \\
\text { Si hay elementos clichés } \\
\text { y/o automáticos en el } \\
\text { discurso, estos no opacan } \\
\text { la capacidad reflexiva que } \\
\text { muestra el P. }\end{array}$ & $\begin{array}{l}\text { El P muestra una } \\
\text { motivación intrínseca } \\
\text { por establecer un foco } \\
\text { sobre los EM, dando } \\
\text { la impresión de un } \\
\text { deseo espontáneo por } \\
\text { reflexionar, compartir } \\
\text { y explicar de forma } \\
\text { profunda la propia } \\
\text { experiencia. No se } \\
\text { observan discursos } \\
\text { clichés ni automáticos, } \\
\text { evidenciándose una } \\
\text { integración original de } \\
\text { elementos observables } \\
\text { a lo interno. }\end{array}$ \\
\hline
\end{tabular}




\section{Opacidad de los estados mentales}

\begin{tabular}{|c|c|c|c|c|c|}
\hline & 1 & 2 & 3 & 4 & 5 \\
\hline 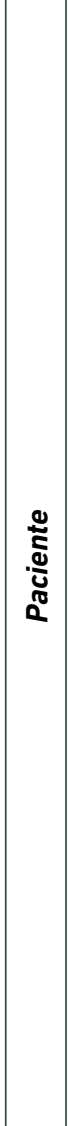 & $\begin{array}{l}\text { El P parece tener } \\
\text { total certeza de } \\
\text { lo que ocurre en } \\
\text { la mente de otros } \\
\text { (incluido el T) o } \\
\text { "cómo son las } \\
\text { cosas" o "deberían } \\
\text { ser", por lo que sus } \\
\text { EM parecen ser la } \\
\text { única "verdad". Es } \\
\text { posible apreciar } \\
\text { un aumento del } \\
\text { arousal manifestado } \\
\text { como un afecto } \\
\text { desbordado y/o } \\
\text { un discurso no } \\
\text { integrado, impreciso } \\
\text { o incluso bizarro. En } \\
\text { términos globales, } \\
\text { se aprecia una total } \\
\text { omnisciencia. }\end{array}$ & $\begin{array}{l}\text { Pese a que la actitud } \\
\text { del P denota certeza } \\
\text { respecto a los EM de } \\
\text { otros (incluido el T) y/o } \\
\text { "cómo son realmente las } \\
\text { cosas" o "deberían ser", da } \\
\text { cuenta de aspectos de los } \\
\text { demás que aun están más } \\
\text { allá de su comprensión } \\
\text { o conocimiento, por lo } \\
\text { que es posible describir } \\
\text { al consultante como } \\
\text { parcialmente omnisciente. }\end{array}$ & $\begin{array}{l}\text { El P habla sobre los } \\
\text { EM de otros (incluido } \\
\text { el T), ofreciendo } \\
\text { información } \\
\text { adicional que } \\
\text { avala la precisión } \\
\text { de sus juicios } \\
\text { sobre la mente de } \\
\text { otros. Aun así, el } \\
\text { P no asume una } \\
\text { actitud de experto } \\
\text { sobre el mundo } \\
\text { interno de otros o } \\
\text { de "como son las } \\
\text { cosas" o "deberían } \\
\text { ser". Si bien el } \\
\text { reconocimiento de } \\
\text { la opacidad de los } \\
\text { EM no se aprecia } \\
\text { explícitamente } \\
\text { a través del } \\
\text { discurso, puede ser } \\
\text { deductivamente } \\
\text { establecido a partir } \\
\text { de su curiosidad } \\
\text { y/o apertura a } \\
\text { imaginar afectos y } \\
\text { cogniciones en otros } \\
\text { o de "cómo es el } \\
\text { mundo" }\end{array}$ & $\begin{array}{l}\text { El P habla sobre los EM } \\
\text { de otros (incluido el T), } \\
\text { ofreciendo información } \\
\text { adicional que avala la } \\
\text { precisión de sus juicios } \\
\text { sobre la mente de otros. } \\
\text { Además, explicita a través } \\
\text { de su discurso que su } \\
\text { respuesta se basa en su } \\
\text { experiencia personal y/o } \\
\text { propio punto de vista ("yo } \\
\text { creo...", "yo pienso ...") y no } \\
\text { puede estar totalmente } \\
\text { seguro ("tal vez...., "es } \\
\text { posible que..."). La mayor } \\
\text { parte del tiempo asume una } \\
\text { actitud curiosa en relación a } \\
\text { los EM de otros. }\end{array}$ & $\begin{array}{l}\text { La imposibilidad de } \\
\text { llegar a conocer con } \\
\text { total certeza cómo } \\
\text { los otros (incluido } \\
\text { el T) experiencian la } \\
\text { realidad es tolerada } \\
\text { e integrada en el } \\
\text { discurso como } \\
\text { algo normal. Hay } \\
\text { un reconocimiento } \\
\text { explícito y total de } \\
\text { que la experiencia } \\
\text { pertenece solamente } \\
\text { al P y no representa } \\
\text { "cómo son realmente } \\
\text { las cosas". El P puede } \\
\text { ser caracterizado } \\
\text { por su apertura } \\
\text { y curiosidad y un } \\
\text { discurso que asume } \\
\text { una cualidad de "tal } \\
\text { vez". }\end{array}$ \\
\hline
\end{tabular}




\begin{tabular}{|c|c|c|c|c|c|}
\hline \multicolumn{6}{|c|}{ 3. Comunicación Contingente } \\
\hline & 1 & 2 & 3 & 4 & 5 \\
\hline 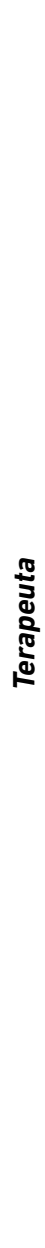 & $\begin{array}{l}\text { Sin considerar } \\
\text { la perspectiva } \\
\text { del P, el T realiza } \\
\text { intervenciones que } \\
\text { imponen un punto } \\
\text { de vista personal } \\
\text { que no toma en } \\
\text { cuenta la interacción } \\
\text { terapéutica actual. } \\
\text { Ejemplos de esto } \\
\text { son: cambios } \\
\text { repentinos de tema, } \\
\text { interrupciones } \\
\text { para imponer } \\
\text { ideas personales } \\
\text { o interpretaciones } \\
\text { sin contexto o } \\
\text { evidencia. En } \\
\text { general, el T puede } \\
\text { ser descrito como } \\
\text { emocionalmente no } \\
\text { sintónico con su P, } \\
\text { y por lo tanto, no lo } \\
\text { sigue. }\end{array}$ & $\begin{array}{l}\text { A pesar de tener en } \\
\text { cuenta la interacción } \\
\text { terapéutica actual, el T no } \\
\text { está en sintonía y/o no } \\
\text { sigue lo que el P trata de } \\
\text { comunicar, asumiendo a } \\
\text { veces un papel de control. } \\
\text { Sus intervenciones pueden } \\
\text { ser en exceso teóricas, } \\
\text { irrelevantes, orientadas a } \\
\text { criticar y/o tener un nivel } \\
\text { de complejidad que hacen } \\
\text { que sea difícil de entender } \\
\text { para el P. }\end{array}$ & $\begin{array}{l}\text { El T parece estar } \\
\text { conectado al } \\
\text { discurso del P, pero } \\
\text { su intervención se } \\
\text { orienta a aspectos } \\
\text { más básicos y } \\
\text { superficiales, sin } \\
\text { tener en cuenta } \\
\text { los elementos } \\
\text { más relevantes } \\
\text { que transmite su } \\
\text { interlocutor. Cuando } \\
\text { el tema que se } \\
\text { discute o el foco } \\
\text { de la conversación } \\
\text { cambia, la } \\
\text { intervención } \\
\text { permanece } \\
\text { orientada a aspectos } \\
\text { superficiales. } \\
\text { Algunas } \\
\text { intervenciones } \\
\text { pueden ser en } \\
\text { exceso teórico o } \\
\text { tener un nivel de } \\
\text { complejidad que } \\
\text { podría ser algo } \\
\text { difícil de entender } \\
\text { para el P en algunos } \\
\text { momentos. }\end{array}$ & $\begin{array}{l}\text { El T está claramente } \\
\text { conectado con el discurso } \\
\text { de su P y, la mayoría de las } \\
\text { veces está emocionalmente } \\
\text { en sintonía. Por lo } \\
\text { tanto, la mayoría de sus } \\
\text { intervenciones están "en } \\
\text { línea" con los aspectos } \\
\text { verbales y no verbales } \\
\text { mostrados por el P, teniendo } \\
\text { en cuenta aspectos } \\
\text { importantes de lo que él/ella } \\
\text { comunica. Cuando el tema } \\
\text { que se discute o el foco de } \\
\text { la conversación cambia, la } \\
\text { intervención sigue orientada } \\
\text { a aspectos importantes del } \\
\text { discurso del P. La mayoría } \\
\text { de las intervenciones se } \\
\text { formulan a un nivel de } \\
\text { complejidad que puede ser } \\
\text { fácilmente comprendido por } \\
\text { el P. }\end{array}$ & $\begin{array}{l}\text { El T parece estar } \\
\text { en sintonía verbal } \\
\text { y no verbal con el } \\
\text { comportamiento, la } \\
\text { emoción y el discurso } \\
\text { del P. El T toma en } \\
\text { cuenta los aspectos } \\
\text { más importantes } \\
\text { mostrados por el P, } \\
\text { y puede participar } \\
\text { en la explicitación } \\
\text { de otros que todavía } \\
\text { no emergen. Las } \\
\text { intervenciones se } \\
\text { formulan en un nivel } \\
\text { de complejidad que } \\
\text { puede ser fácilmente } \\
\text { entendido por el } \\
\text { otro. Las acciones } \\
\text { terapéuticas se } \\
\text { vinculan a otras } \\
\text { previas y/o pueden } \\
\text { adaptarse de forma } \\
\text { flexible (es decir, sigue } \\
\text { de forma contingente a } \\
\text { los Ps en un cambio de } \\
\text { temas si es necesario) } \\
\text { con el fin de seguir } \\
\text { contingentemente } \\
\text { al P o crear nuevas } \\
\text { oportunidades para } \\
\text { profundizar en su } \\
\text { experiencia. }\end{array}$ \\
\hline 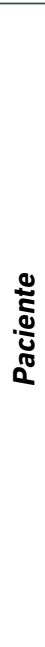 & $\begin{array}{l}\text { El P parece no estar } \\
\text { siguiendo a su T, } \\
\text { dando la sensación } \\
\text { de un monólogo o } \\
\text { bien, de no estar } \\
\text { escuchándolo. } \\
\text { Sus respuestas, } \\
\text { si las hay, no } \\
\text { corresponden } \\
\text { a las preguntas } \\
\text { del T, pudiéndose } \\
\text { observar incluso } \\
\text { cambios bruscos de } \\
\text { tema o intentos de } \\
\text { control sobre el otro. }\end{array}$ & $\begin{array}{l}\text { El P toma en cuenta } \\
\text { las intervenciones del } \\
\text { T e incluso responde } \\
\text { varias veces a ellas, sin } \\
\text { embargo, el foco de su } \\
\text { discurso está orientado } \\
\text { a abordar aspectos de } \\
\text { la conversación que son } \\
\text { más autorreferentes } \\
\text { y/o irrelevantes para la } \\
\text { interacción actual. Pueden } \\
\text { observarse interrupciones, } \\
\text { actitudes evasivas o } \\
\text { cambios continuos de } \\
\text { tema. Esto puede ocurrir } \\
\text { a pesar de la insistencia } \\
\text { del T. }\end{array}$ & $\begin{array}{l}\text { El P sigue } \\
\text { pasivamente las } \\
\text { intervenciones del } \\
\text { T, pudiendo mostrar } \\
\text { cierto grado de } \\
\text { acuerdo e incluso } \\
\text { complacencia. Aun } \\
\text { así, hay un esfuerzo } \\
\text { por acoplarse } \\
\text { y colaborar. } \\
\text { Algunas de las } \\
\text { intervenciones } \\
\text { del T parecen ser } \\
\text { usadas por el P para } \\
\text { reflexionar, pero en } \\
\text { un nivel concreto y/o } \\
\text { superficial. }\end{array}$ & $\begin{array}{l}\text { La mayoría de las veces el P } \\
\text { sigue de forma colaborativa } \\
\text { las intervenciones del T, } \\
\text { aprovechándolas para } \\
\text { reflexionar. Sin embargo, } \\
\text { puede señalar cuando está } \\
\text { en desacuerdo o considera } \\
\text { que un nuevo tema o } \\
\text { aspecto específico necesita } \\
\text { ser abordado. }\end{array}$ & $\begin{array}{l}\text { El P participa activa y } \\
\text { colaborativamente en } \\
\text { la construcción de un } \\
\text { contexto terapéutico } \\
\text { que potencia la } \\
\text { mentalización, } \\
\text { pudiendo incluso "ir } \\
\text { más allá" de lo que se } \\
\text { espera a partir de las } \\
\text { intervenciones del T. } \\
\text { Aun así, puede señalar } \\
\text { asertivamente cuando } \\
\text { está en desacuerdo } \\
\text { o considera que un } \\
\text { nuevo tema o aspecto } \\
\text { específico necesita ser } \\
\text { abordado. }\end{array}$ \\
\hline
\end{tabular}




\section{Naturaleza dinámica de los estados mentales}

\begin{tabular}{|c|c|c|c|c|c|}
\hline & 1 & 2 & 3 & 4 & 5 \\
\hline 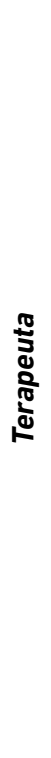 & $\begin{array}{l}\text { El T no toma en } \\
\text { cuenta la naturaleza } \\
\text { dinámica de los } \\
\text { EM durante su } \\
\text { intervención, } \\
\text { existiendo } \\
\text { posibilidades } \\
\text { claras para hacerlo, } \\
\text { perdiendo una } \\
\text { clara posibilidad } \\
\text { de favorecer este } \\
\text { aspecto en el P }\end{array}$ & $\begin{array}{l}\text { El T realiza algunas } \\
\text { intervenciones que } \\
\text { incorporan la naturaleza } \\
\text { dinámica de los EM, sin } \\
\text { embargo, estas acciones } \\
\text { podrían utilizar clichés } \\
\text { (“Bueno, así son las } \\
\text { cosas"...) y/o imponer } \\
\text { ideas, hacer comentarios } \\
\text { generales sobre EM sin } \\
\text { convertirse en una acción } \\
\text { terapéutica orientada a } \\
\text { invitar al P a reflexionar } \\
\text { sobre este aspecto. }\end{array}$ & $\begin{array}{l}\text { El T realiza } \\
\text { intervenciones } \\
\text { que promueven la } \\
\text { reflexión sobre la } \\
\text { naturaleza dinámica } \\
\text { de los EM de una } \\
\text { manera básica y } \\
\text { concreta, elaborando } \\
\text { comentarios } \\
\text { generales, preguntas } \\
\text { cerradas ("¿crees } \\
\text { que lo ven como } \\
\text { tu?", ¿Era pena } \\
\text { o rabia?, ¿Qué } \\
\text { hiciste para que } \\
\text { no se den cuenta } \\
\text { de tu malestar?"), } \\
\text { o preguntas } \\
\text { de demanda } \\
\text { descontextualizadas. }\end{array}$ & $\begin{array}{l}\text { El T realiza algunas acciones } \\
\text { que buscan promover } \\
\text { considerablemente la } \\
\text { reflexión sobre la naturaleza } \\
\text { dinámica de los EM, } \\
\text { realizando intervenciones } \\
\text { y preguntas relevantes } \\
\text { y contextualizadas que } \\
\text { demandan el uso la función } \\
\text { reflexiva. }\end{array}$ & $\begin{array}{l}\text { El T promueve } \\
\text { activamente una } \\
\text { reflexión clara y } \\
\text { profunda sobre la } \\
\text { naturaleza dinámica } \\
\text { de los EM realizando } \\
\text { intervenciones y } \\
\text { preguntas relevantes } \\
\text { y contextualizadas que } \\
\text { demandan el uso la } \\
\text { función reflexiva. }\end{array}$ \\
\hline 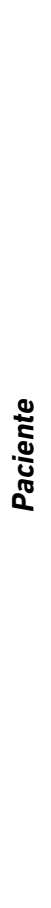 & $\begin{array}{l}\text { El P no incorpora la } \\
\text { naturaleza dinámica } \\
\text { de los EM en su } \\
\text { discurso ya sea } \\
\text { espontáneamente } \\
\text { o en respuesta a } \\
\text { las preguntas del } \\
\text { T, aunque haya una } \\
\text { oportunidad para } \\
\text { hacerlo. }\end{array}$ & $\begin{array}{l}\text { El P incorpora a su } \\
\text { discurso la naturaleza } \\
\text { dinámica de los EM } \\
\text { de una manera que } \\
\text { parece antinatural y } \\
\text { emocionalmente poco } \\
\text { consistente, dando la } \\
\text { impresión de una acción } \\
\text { utilitaria, como tratar } \\
\text { de convencer al T, ser } \\
\text { condescendiente, o tratar } \\
\text { de "salir del paso". Todas } \\
\text { estas acciones podrían } \\
\text { caracterizarse por ser sólo } \\
\text { aparentemente reflexivas. } \\
\text { El codificador puede } \\
\text { tener la impresión de que } \\
\text { el discurso del P no es } \\
\text { creíble, es irrelevante para } \\
\text { el proceso y/o tiene un } \\
\text { objetivo exclusivamente } \\
\text { autoafirmativo. }\end{array}$ & $\begin{array}{l}\text { El P incorpora } \\
\text { en su discurso la } \\
\text { naturaleza dinámica } \\
\text { de los EM de una } \\
\text { manera básica y/o } \\
\text { concreta, a un nivel } \\
\text { bastante descriptivo: } \\
\text { por ejemplo, se } \\
\text { da cuenta de la } \\
\text { existencia de } \\
\text { diferentes puntos de } \\
\text { vista, o emociones } \\
\text { contradictorias, pero } \\
\text { no se refiere a sus } \\
\text { implicaciones. Es } \\
\text { posible observar el } \\
\text { uso de clichés en } \\
\text { esta categoría. A } \\
\text { diferencia del punto } \\
\text { 2, aquí podemos } \\
\text { ver una intención } \\
\text { reflexiva asociada } \\
\text { con la naturaleza } \\
\text { dinámica de los EM. }\end{array}$ & $\begin{array}{l}\text { El P incorpora en su } \\
\text { discurso aspectos dinámicos } \\
\text { de los EM, siendo capaz } \\
\text { de reconocer y tolerar } \\
\text { contradicciones, diferentes } \\
\text { puntos de vista y / o su } \\
\text { naturaleza cambiante, tanto } \\
\text { en sí mismo como en los } \\
\text { demás. }\end{array}$ & $\begin{array}{l}\text { El P incorpora en su } \\
\text { discurso aspectos } \\
\text { dinámicos de los } \\
\text { EM, siendo capaz de } \\
\text { reconocer, tolerar } \\
\text { y coherentemente } \\
\text { integrar } \\
\text { contradicciones, } \\
\text { diferentes puntos de } \\
\text { vista y/o su naturaleza } \\
\text { cambiante, tanto en } \\
\text { sí mismo como en los } \\
\text { demás. La emoción que } \\
\text { acompaña al discurso } \\
\text { es emocionalmente } \\
\text { consistente, y puede } \\
\text { dar la impresión de un } \\
\text { genuino surgimiento } \\
\text { algo nuevo para el P. }\end{array}$ \\
\hline
\end{tabular}




\begin{tabular}{|c|c|c|c|c|c|}
\hline \multicolumn{6}{|c|}{ 5. Imaginar causalidad } \\
\hline & 1 & 2 & 3 & 4 & 5 \\
\hline 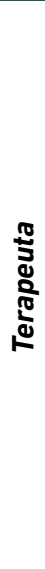 & $\begin{array}{l}\text { El T no toma en } \\
\text { cuenta la causalidad } \\
\text { de los EM durante } \\
\text { su intervención, } \\
\text { existiendo } \\
\text { posibilidades } \\
\text { claras para hacerlo, } \\
\text { perdiendo una } \\
\text { clara posibilidad } \\
\text { de favorecer este } \\
\text { aspecto en el P }\end{array}$ & $\begin{array}{l}\text { El T realiza algunas } \\
\text { intervenciones que } \\
\text { incorporan la causalidad } \\
\text { de los EM, sin embargo, } \\
\text { estas acciones podrían } \\
\text { utilizar clichés ("Bueno, } \\
\text { así son las cosas"...) y/o } \\
\text { imponer ideas, hacer } \\
\text { comentarios generales } \\
\text { sobre EM sin convertirse } \\
\text { en una acción terapéutica } \\
\text { orientada a invitar al P } \\
\text { a reflexionar sobre este } \\
\text { aspecto. }\end{array}$ & $\begin{array}{l}\text { El T realiza } \\
\text { intervenciones } \\
\text { que promueven } \\
\text { la reflexión sobre } \\
\text { la causalidad de } \\
\text { los EM de una } \\
\text { manera básica y } \\
\text { concreta, elaborando } \\
\text { comentarios } \\
\text { generales, preguntas } \\
\text { cerradas ("¿crees } \\
\text { que B se debió a } \\
\text { A?) o preguntas } \\
\text { de demanda } \\
\text { descontextualizadas. }\end{array}$ & $\begin{array}{l}\text { El T realiza algunas } \\
\text { intervenciones que } \\
\text { buscan promover } \\
\text { considerablemente } \\
\text { la reflexión sobre la } \\
\text { causalidad de los EM, } \\
\text { realizando intervenciones } \\
\text { y preguntas relevantes } \\
\text { y contextualizadas que } \\
\text { demandan el uso la función } \\
\text { reflexiva. }\end{array}$ & $\begin{array}{l}\text { El T promueve } \\
\text { activamente una } \\
\text { reflexión clara y } \\
\text { profunda sobre la } \\
\text { influencia de los EM } \\
\text { sobre la conducta, } \\
\text { dinámicas relacionales } \\
\text { o el desarrollo } \\
\text { psicológico (y } \\
\text { viceversa), realizando } \\
\text { intervenciones y } \\
\text { preguntas relevantes } \\
\text { y contextualizadas que } \\
\text { demandan el uso la } \\
\text { función reflexiva. }\end{array}$ \\
\hline & $\begin{array}{l}\text { El P no incorpora } \\
\text { la causalidad } \\
\text { de los EM en su } \\
\text { discurso ya sea } \\
\text { espontáneamente } \\
\text { o en respuesta a } \\
\text { las preguntas del } \\
\text { T, aunque haya una } \\
\text { oportunidad para } \\
\text { hacerlo. }\end{array}$ & $\begin{array}{l}\text { El P incorpora a su } \\
\text { discurso la causalidad } \\
\text { de los EM de una manera } \\
\text { que parece antinatural } \\
\text { y emocionalmente poco } \\
\text { consistente, dando la } \\
\text { impresión de una acción } \\
\text { utilitaria, como tratar } \\
\text { de convencer al T, ser } \\
\text { condescendiente, o tratar } \\
\text { de "salir del paso". Todas } \\
\text { estas acciones podrían } \\
\text { caracterizarse por ser sólo } \\
\text { aparentemente reflexivas. } \\
\text { El codificador puede } \\
\text { tener la impresión de que } \\
\text { el discurso del P no es } \\
\text { creíble, es irrelevante para } \\
\text { el proceso y/o tiene un } \\
\text { objetivo exclusivamente } \\
\text { autoafirmativo. }\end{array}$ & $\begin{array}{l}\text { El P incorpora } \\
\text { en su discurso la } \\
\text { causalidad de los } \\
\text { EM de una manera } \\
\text { básica y/o concreta, } \\
\text { a un nivel bastante } \\
\text { descriptivo: por } \\
\text { ejemplo, se refiere } \\
\text { a sus dificultades } \\
\text { para regular el } \\
\text { miedo debido a } \\
\text { experiencias vividas } \\
\text { en el pasado, pero } \\
\text { no explica cómo } \\
\text { estas experiencias } \\
\text { se relacionan con } \\
\text { esta dificultad. A } \\
\text { diferencia del punto } \\
\text { 2, aquí podemos } \\
\text { ver una intención } \\
\text { reflexiva asociada } \\
\text { con la causalidad de } \\
\text { los EM. }\end{array}$ & $\begin{array}{l}\text { El P incorpora en su } \\
\text { discurso la causalidad de } \\
\text { los EM, siendo capaz de } \\
\text { profundizar en la reflexión } \\
\text { sobre la influencia de estos } \\
\text { EM sobre la conducta, } \\
\text { dinámicas relacionales o } \\
\text { el desarrollo psicológico (y } \\
\text { viceversa). }\end{array}$ & $\begin{array}{l}\text { El P incorpora en su } \\
\text { discurso la causalidad } \\
\text { de los EM, siendo capaz } \\
\text { de reconocer múltiples, } \\
\text { complejas y profundas } \\
\text { influencias entre la } \\
\text { conducta, dinámicas } \\
\text { relacionales o el } \\
\text { desarrollo psicológico } \\
\text { y los EM (y viceversa). } \\
\text { La emoción que } \\
\text { acompaña al discurso } \\
\text { es emocionalmente } \\
\text { consistente, y puede } \\
\text { dar la impresión de un } \\
\text { genuino surgimiento } \\
\text { algo nuevo para el P. }\end{array}$ \\
\hline
\end{tabular}




\section{Foco en el momento presente}

\begin{tabular}{|c|c|c|c|c|c|}
\hline \multicolumn{6}{|c|}{ 6. Foco en el momento presente } \\
\hline & 1 & 2 & 3 & 4 & 5 \\
\hline 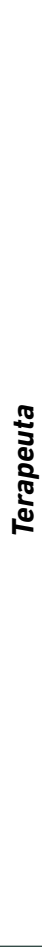 & $\begin{array}{l}\text { El T realiza acciones } \\
\text { que promueven } \\
\text { la desregulación } \\
\text { del afecto del } \\
\text { P. Un ejemplo } \\
\text { corresponde a } \\
\text { intervenciones } \\
\text { que pueden ser } \\
\text { caracterizadas como } \\
\text { retraumatizadoras. }\end{array}$ & $\begin{array}{l}\text { El T colabora con } \\
\text { la desregulación o } \\
\text { estancamiento (por } \\
\text { ejemplo, insistir en la } \\
\text { descripción situaciones } \\
\text { pasadas que no favorecen } \\
\text { la reflexión) del paciente } \\
\text { tanto por acciones que } \\
\text { mantienen o aumentan } \\
\text { el arousal o por el } \\
\text { mantenimiento de una } \\
\text { actitud pasiva. Es posible } \\
\text { que el t haga mención al } \\
\text { presente, pero esto es un } \\
\text { aspecto secundario que } \\
\text { no tiene como intención } \\
\text { promover la focalización } \\
\text { en el ahora. En algunos } \\
\text { momentos el t puede } \\
\text { parecer distraído o } \\
\text { atento a temas distintos } \\
\text { al espacio terapéutico } \\
\text { inmediato (hablar } \\
\text { por teléfono, escribir } \\
\text { excesivamente). }\end{array}$ & $\begin{array}{l}\text { El T lleva a cabo } \\
\text { algunas acciones } \\
\text { que dan cuenta } \\
\text { implícitamente de } \\
\text { una búsqueda por } \\
\text { focalizar al P en el } \\
\text { presente ("ahora } \\
\text { que lo pienso", "eso } \\
\text { me hace sentir } \\
\text {..., "'¿estás triste? } \\
\text {...) promoviendo } \\
\text { la regulación del } \\
\text { P de una manera } \\
\text { concreta y/o básica. }\end{array}$ & $\begin{array}{l}\text { Muchas de las acciones } \\
\text { terapéuticas realizadas } \\
\text { por el T están orientadas } \\
\text { a enfocar al P en el tiempo } \\
\text { presente, lo que se observa } \\
\text { a través del discurso tanto } \\
\text { implícitamente ("ahora } \\
\text { que lo pienso", "eso me } \\
\text { hace sentir ..."), como una } \\
\text { invitación explícita ("¿Qué } \\
\text { estás sintiendo ahora?"). } \\
\text { Estas intervenciones se } \\
\text { caracterizan en general } \\
\text { porque potencialmente } \\
\text { buscan promueven la } \\
\text { regulación del P. }\end{array}$ & $\begin{array}{l}\text { El T trae activamente } \\
\text { al P al momento } \\
\text { presente, deteniendo } \\
\text { las reflexiones que } \\
\text { estancan la interacción } \\
\text { en el pasado o en } \\
\text { eventos futuros. } \\
\text { Estas intervenciones } \\
\text { asumen la forma } \\
\text { de una invitación } \\
\text { y son coherentes } \\
\text { y contingentes, } \\
\text { incluso cuando el } \\
\text { T insiste en que un } \\
\text { P se niega explícita } \\
\text { o implícitamente a } \\
\text { permanecer en el } \\
\text { presente. }\end{array}$ \\
\hline & $\begin{array}{l}\text { El P muestra un } \\
\text { afecto desbordado } \\
\text { sobre el cual se } \\
\text { orienta todo el foco } \\
\text { de su atención. } \\
\text { La aparición de } \\
\text { esta emoción no } \\
\text { se asocia con } \\
\text { un insight u otro } \\
\text { proceso relacionado } \\
\text { con el cambio } \\
\text { terapéutico. En } \\
\text { otras ocasiones el } \\
\text { P puede recurrir } \\
\text { a respuestas } \\
\text { que parecen } \\
\text { automáticas donde, } \\
\text { si bien no parece } \\
\text { desbordado, da } \\
\text { la sensación al } \\
\text { codificador de que } \\
\text { rechaza estar aquí y } \\
\text { ahora, por ejemplo, } \\
\text { a través del uso de } \\
\text { monosílabos. }\end{array}$ & $\begin{array}{l}\text { El P está atrapado en } \\
\text { un discurso reiterativo } \\
\text { caracterizado por el } \\
\text { recuento de historias } \\
\text { asociadas con } \\
\text { eventos pasados o } \\
\text { futuros (por ejemplo, } \\
\text { permanecer en un } \\
\text { discurso autoafirmativo, } \\
\text { o que rememora } \\
\text { insistentemente } \\
\text { momentos difíciles) o } \\
\text { con un afecto que intenta } \\
\text { infructuosamente regular. }\end{array}$ & $\begin{array}{l}\text { El discurso del P } \\
\text { está focalizado en } \\
\text { acontecimientos } \\
\text { pasados o futuros, } \\
\text { sin embargo, puede } \\
\text { reflexionar sobre } \\
\text { ellos en el momento } \\
\text { presente dando } \\
\text { cuenta de una } \\
\text { capacidad incipiente } \\
\text { para regular el } \\
\text { afecto y un esfuerzo } \\
\text { por estar en el } \\
\text { presente. }\end{array}$ & $\begin{array}{l}\text { El discurso del P está } \\
\text { focalizado en el presente, } \\
\text { mostrando indicadores } \\
\text { explícitos de esto en el } \\
\text { discurso ("ahora que lo } \\
\text { pienso ...", "eso me hace } \\
\text { sentir ..., "yo pienso } \\
\text { que") dando cuenta de su } \\
\text { capacidad para regular el } \\
\text { afecto. }\end{array}$ & $\begin{array}{l}\text { El foco del discurso del } \\
\text { P se refiere al presente, } \\
\text { de modo que la } \\
\text { referencia a aspectos } \\
\text { pasados o futuros sólo } \\
\text { da un contexto general } \\
\text { a lo que parece estar } \\
\text { experimentando en el } \\
\text { momento actual. La } \\
\text { calidad de la historia } \\
\text { da la impresión } \\
\text { al codificador de } \\
\text { estar espontánea y } \\
\text { vívidamente conectado } \\
\text { con emociones y } \\
\text { pensamientos en el } \\
\text { presente. }\end{array}$ \\
\hline
\end{tabular}

